\title{
Assembly of chitosan support matrix with gallic acid-functionalized nanoparticles
}

\author{
J. Lamarra ${ }^{\mathrm{a}, \mathrm{b}}$, L. Giannuzzi ${ }^{\mathrm{a}, \mathrm{b}}$, S. Rivero ${ }^{\mathrm{a}, \mathrm{b}}$, A. Pinotti $^{\mathrm{a}, \mathrm{c}, *}$ \\ a Center for Research and Development in Food Cryotechnology (CCT-CONICET La Plata, CIC), 47 and 116, La Plata 1900, Argentina \\ ${ }^{b}$ Faculty of Exact Sciences, UNLP, Argentina \\ c Faculty of Engineering, UNLP, Argentina
}

\section{A R T I C L E I N F O}

\section{Article history:}

Received 22 December 2016

Accepted 15 May 2017

Available online 16 May 2017

\section{Keywords:}

Chitosan nanoparticles

Nanocomposites

Antimicrobial properties

Controlled release

Gallic acid

\begin{abstract}
A B S T R A C T
The incorporation of gallic acid (GA) in a direct way or into nanoparticles included in chitosan edible films appears as a suitable approach to increase its preservation upon adverse conditions.

The addition of nanoparticles to chitosan-based matrices resulted in improvements in their solubility, swelling, and mechanical properties. It is worth noting that by means of the nanoencapsulation, the release process can be modulated in relation to the delivery of GA included directly in the matrix, releasing the agent at a lower rate for a longer time. Films containing functionalized nanoparticles are promising as a means to develop tailor-made support matrices for improving the shelf stability of the included active compound. From the point of view of the antimicrobial activity, all studied films showed bacteriostatic activity against Staphylococcus aureus ATCC 25923, Escherichia coli ATCC 25922, Salmonella spp. and Candida vinaria. The results suggest that active films with nanoparticles could be a potential candidate for the support and controlled release of active compounds such as gallic acid.
\end{abstract}

@ 2017 Elsevier B.V. All rights reserved.

\section{Introduction}

Chitosan (Ch), a cationic biodegradable polysaccharide, contains $\beta$ [1-4]-linked 2-acetamido-2-deoxy-D-glucopyranose and 2-amino-2deoxy-D-glucopyranose units [1]. This biopolymer has amine groups highly reactive in its structure, which allow modifying its functionality by means of the incorporation of active compounds or by obtaining micro- and nanoparticles [2-5].

Gallic acid (3,4,5-trihydroxybenzoic acid) is a phenolic acid that can be extracted from gallnuts, tea leaves, oak bark, and other plants [6]. Numerous biological properties have been ascribed to the gallic acid such as anti-inflammatory, anti-mutagenic, and antioxidant [7]. In addition, GA possesses antimicrobial activity [8] and has been identified as a natural crosslinker that can modify the mechanical performance of natural polymers, promoting its use as a food-packaging material [9] and also enhances elasticity, thus acting as a plasticizer [10].

The development of different strategies to guarantee an adequate preservation of phenolic compounds in the final product is currently the focus of attention of food and pharmaceutical industries.

\footnotetext{
* Corresponding author at: Center for Research and Development in Food Cryotechnology (CCT-CONICET La Plata, CIC), 47 and 116, La Plata 1900, Argentina.

E-mail address: acaimpronta@hotmail.com (A. Pinotti).
}

Encapsulation of these compounds and extracts is an efficient method to include the phenolic compounds into products [11,12], making the handling easier and improving the stability [9]. Specifically, through the use of the nanotechnology, new forms of polymeric supports with loaded nanoparticles can be developed to tailor their properties and modulate the active compound release [13]. According to Bodnar et al. [2] and Merino et al. [14], the combination of loaded nanoparticles with polymeric matrixes could overcome the limitations and drawbacks associated with the use of nanoparticles as delivery systems. This strategy represents an effective technique to protect the active compound during storage and processing.

As reported by Sugita et al. [15], the main advantages of using nanostructures as release systems are related to the fact that the nanoparticles can be tuned in accordance with their application, the inclusion of additives into nanoparticles without chemical reactions and the control and extension of the active compound release.

In this context, the method's influence of incorporation of gallic acid on the properties of chitosan matrixes was analyzed by means of scanning electron microscope (SEM) and X-ray diffraction (XRD). Fourier transform infrared spectroscopy (FTIR) was also employed to characterize the chemical interactions among the compounds. Mathematical models were used to evaluate the transport mechanisms of the active compound and the potential antimicrobial properties were tested by 
the disc diffusion method against yeasts as well as Gram-positive and Gram-negative pathogenic bacteria.

\section{Materials and methods}

Chitosan (Ch), from crab shells with a molecular weight of $3.2 \times 10^{5}$ Da and a deacetylation degree of $85 \%$, was supplied by Polymar Ciência e Nutrição (Fortaleza, Brazil). GA was provided by Sigma-Aldrich Chemical Company (St. Louis, MO, USA). Sodium tripolyphosphate (TPP) and acetic acid were purchased from Anedra (Buenos Aires, Argentina).

\subsection{Preparation of nanoparticles}

Chitosan $0.75 \%(\mathrm{w} / \mathrm{w}$ ) was solubilized in $0.75 \%(\mathrm{v} / \mathrm{v})$ acetic acid solution at $20{ }^{\circ} \mathrm{C}$ under continuous agitation. Afterward, $50 \mathrm{mg}_{\mathrm{GA}} / \mathrm{g}_{\mathrm{Ch}}$ were added to the $\mathrm{Ch}$ solutions. Sodium tripolyphosphate, used as a crosslinking agent, was prepared at the concentration of $2 \%(\mathrm{w} / \mathrm{v})$ [16].

Nanoparticles were synthetized by the ionotropic gelation technique based on a modified method described by Calvo et al. [17]. TPP solution was added dropwise under continuous stirring into the solution containing $\mathrm{Ch}$ and GA until reaching Ch:TPP ratios of 5 and 3 . After completion this process, the obtained suspensions were homogenized for 10 min at $13500 \mathrm{rpm}$ by means of an Ultraturrax T-25 Janke \& Kunkel (IKA-Labortechnik, Germany).

Nanoparticles without GA were prepared following the same procedure previously using a $\mathrm{Ch}$ solution without the addition of the active compound.

For suspensions of chitosan nanoparticles with Ch:TPP ratios of 5 and 3 , the nomenclature used will be $\mathrm{N}_{\mathrm{A}}$ and $\mathrm{N}_{\mathrm{B}}$, respectively. In the case of empty nanoparticles, the label used will be $\mathrm{N}_{\mathrm{AE}}$ and $\mathrm{N}_{\mathrm{BE}}$ for Ch:TPP ratios of 5 and 3, respectively.

\subsection{Suspension analysis}

The zeta potential (ZP) and particle hydrodynamic size of the nanoparticles were determined by a Zetasizer Nano-ZS Malvern Instruments (Worcestershire, England) equipped with a digital correlator Model ZEN3600. The ZP and particle diameter were informed as the average of five determinations per sample. The assays were performed in triplicate.

The global stability of the suspensions of either empty $\left(\mathrm{N}_{\mathrm{AE}}\right.$ and $\left.\mathrm{N}_{\mathrm{BE}}\right)$ or GA loaded nanoparticles $\left(\mathrm{N}_{\mathrm{A}}\right.$ and $\mathrm{N}_{\mathrm{B}}$ ) was carried out by light scattering with a vertical scan analyzer (QuickScan, Beckman Coulter, Fullerton, USA) at room temperature. The suspensions were scanned with a monochromatic light source $(\lambda=850 \mathrm{~nm})$ as a function of the height of the sample tube (ca. $65 \mathrm{~mm}$ ) in quiescent conditions, acquiring transmittance and BS (1620 acquisitions in each scan) [16]. Measurements were performed independently and in triplicate.

The study of the contribution of each component (TPP or TPP and GA) to the interactions was carried out by means of ATR-FTIR technique on either $\mathrm{N}_{\mathrm{AE}}$ and $\mathrm{N}_{\mathrm{BE}}$ or $\mathrm{N}_{\mathrm{A}}$ and $\mathrm{N}_{\mathrm{B}}$ samples, respectively. Spectra were recorded by a Nicolet, iS10 Thermo Scientific (Madison, USA) in the wavenumber range $4000-400 \mathrm{~cm}^{-1}$ by the accumulation of 64 scans at $4 \mathrm{~cm}^{-1}$ resolution. Samples were placed onto the diamond ATR crystal (Smart iTX accessory) for the Nicolet ${ }^{\mathrm{TM}}$ iS $^{\mathrm{TM}} 10$ (Thermo Scientific ${ }^{\mathrm{TM}}$, Madison, USA). Data were analyzed by using the software Omnic 8 (Thermo Scientific, Madison, USA).

\subsection{Film preparation}

A chitosan solution $1.5 \%(\mathrm{w} / \mathrm{w})$ was prepared by solubilization in $1.5 \%(\mathrm{v} / \mathrm{v})$ acetic acid solution as described previously [18]. Ch solutions were separated in four batches of $100 \mathrm{~mL}$ each one, the first one being used as a control and the other three being functionalized with GA. On the second batch, $12.5 \mathrm{mg}$ of gallic acid was directly solubilized in the chitosan filmogenic solution (ChGA) and, $50 \mathrm{~mL}$ suspensions of particles loaded with GA, prepared as described in Section 2.1 Preparation of nanoparticles, were incorporated to the other two batches $\left(\mathrm{ChN}_{\mathrm{A}}\right.$ and $\mathrm{ChN}_{\mathrm{B}}$ ). Chitosan-based films were prepared by casting of filmogenic suspensions and drying in an oven at $37{ }^{\circ} \mathrm{C}$ until reaching a constant weight. The obtained films were conditioned in a controlled room at $20{ }^{\circ} \mathrm{C}$ and $65 \%$ relative humidity ( $\left.\mathrm{RH}\right)$.

From here onwards, nomenclature used will be: $\mathrm{Ch}$ for control chitosan films, ChGA for films of chitosan with the direct addition of GA to the filmogenic solution, $\mathrm{ChN}_{\mathrm{A}}$ and $\mathrm{ChN}_{\mathrm{B}}$ for films with the addition of $\mathrm{N}_{\mathrm{A}}$ or $\mathrm{N}_{\mathrm{B}}$ particles prepared with $\mathrm{Ch} 0.75 \%, 50 \mathrm{~m}_{\mathrm{GA}} / \mathrm{g}_{\mathrm{Ch}}$, and Ch:TPP ratios of 5 and 3 , respectively [16].

A coating thickness gauge Check Line DCN-900 (New York, USA) was used to determine the film thickness. The reported values correspond to the average of at least fourteen measurements at different positions for each sample.

\subsection{Film physical properties}

The moisture content of the film was quantified measuring its weight loss, upon drying in an oven at $105^{\circ} \mathrm{C}$ until reaching a constant weight; results were expressed in grams of water per $100 \mathrm{~g}$ of sample. Samples were analyzed in triplicate.

Film solubility was determined according to Rivero et al. [18]. Samples of $3 \times 3 \mathrm{~cm}$ were weighed and placed into test beakers with $100 \mathrm{~mL}$ of deionized water under constant stirring for $1 \mathrm{~h}$ at $20^{\circ} \mathrm{C}$. The remaining pieces after soaking were dried in an oven at $105 \pm 1{ }^{\circ} \mathrm{C}$ until reaching a constant weight. The informed results corresponded to the mean of three replicate assays.

The swelling capacity of films was measured by immersion of previously weighed film pieces in $100 \mathrm{~mL}$ of distilled water during $60 \mathrm{~min}$ [18]. After that, the samples were recovered and dried to remove the excess of surface water and re-weighed. The swelling was calculated as described by Rivero et al. [18]. Samples were analyzed at least in triplicate.

Water vapor permeability (WVP) assays were carried out based on a modified ASTM [19] method E96 by using a home-made permeation cell which was maintained at $20{ }^{\circ} \mathrm{C}$ as described in previous work [16]. After steady-state condition was reached, the permeation cells were weight over $9 \mathrm{~h}$. Each reported value corresponded at least to four determinations.

For the evaluation of the UV barrier properties, opacity and transparency, rectangular film samples were placed in a quartz spectrophotometer cell. A UV-visible Spectrophotometer DU 650 (Beckman, USA) was used to record the absorbance.

The reported values correspond to the arithmetic mean of three individual determinations.

The area under the recorded curve, defined as film opacity, was determined by an integration procedure between 400 and $700 \mathrm{~nm}$ [20]. Opacity was reported as absorbance units per nanometers (AUxnm).

Meanwhile, film transparency was calculated following the method described by Zhang and Han [21] using the ratio between the absorbance at $600 \mathrm{~nm}$ and film thickness. The informed results, expressed as $A_{600} \mathrm{~mm}^{-1}$, correspond to the average value of three replicate tests.

\subsection{Mechanical properties}

For quasi-static trial in uniaxial condition, a constant force ramp rate of $0.3 \mathrm{~N} \mathrm{~min}^{-1}$ was programmed to register the stress-strain curves up to $18 \mathrm{~N}$ or until rupture from film strips, using a dynamic-mechanical thermal equipment Q800 (TA Instruments, New Castle, USA) [22]. In order to calculate the elastic modulus $\left(\mathrm{E}_{\mathrm{C}}\right)$, stress-strain curves were fitted with the following equation:

$\sigma_{\mathrm{V}}=\mathrm{E}_{\mathrm{C}} \varepsilon_{\mathrm{V}} \mathrm{e}^{-\varepsilon_{\mathrm{V}} \mathrm{K}}$ 
where, $\mathrm{E}_{\mathrm{C}}$ is the elastic modulus, $\varepsilon_{\mathrm{v}}$ and $\sigma_{\mathrm{v}}$ are the true strain and the true stress respectively, and $\mathrm{K}$ is a constant regarded as a fitting parameter. Samples were analyzed at least in triplicate.

Percentage elongation at break (E) and maximum tensile strength (TS) of each sample were assessed by using a texturometer TA.XT2i-Stable Micro Systems (England). Film probes were stretched with a tension grip system A/TG at a constant rate of $0.5 \mathrm{~mm} \mathrm{~s}^{-1}$. Texture Expert Exceed software was used to record the curves of force $(\mathrm{N})$ as a function of deformation $(\mathrm{mm})$. As stated by Siracusa et al. [23] the area under this curve, expressed in J, represents the material tenacity. The informed values correspond to the arithmetic mean of six individual determinations.

\subsection{Structural studies}

The examination of the film morphology was performed through the use of FEI model Quanta 200 scanning electron microscope (The Netherlands). Before analyzing $\mathrm{Ch}$, ChGA films, and nanocomposites $\left(\mathrm{ChN}_{\mathrm{A}}\right.$ and $\mathrm{ChN}_{\mathrm{B}}$ ) with low vacuum, they were cryogenically frozen in liquid nitrogen, fractured and mounted on bronze stubs through a doublesided adhesive carbon tape. In addition, the failures of the samples submitted to stretch by means of the texturometer were studied by direct observation of the structures of the fractured cross-sections.

Specimens were examined without any metal or carbon coating at an acceleration voltage of $15 \mathrm{kV}$.

The structure of the chitosan-based films was also evaluated by means of X-ray diffraction in a Philips PW 3710, X'Pert Pro P Analytical ModelPW3040/60 (Almelo, The Netherlands). The CuK radiation $(1.542 \AA$ ) operated at room temperature was generated at $30 \mathrm{~mA}$ and $40 \mathrm{kV}$, recording the relative intensity in the scattering range of $(2 \theta)$ $3-60^{\circ}$ with a step size $2 \theta 0.02^{\circ}$.

\subsection{Diffusion experiments}

GA was quantified by using a UV-visible Spectrophotometer DU 650 (Beckman, USA). The diffusion of gallic acid was carried out in water at room temperature.

Film pieces of $6 \times 6 \mathrm{~cm}$ were placed on a plastic holder and immersed in $100 \mathrm{~mL}$ of the solvent, which was kept under agitation. Samples of $0.85 \mathrm{~mL}$ were periodically taken from the solution, and the concentrations of GA released from the matrix into the medium were quantified by measuring the absorbance at $269 \mathrm{~nm}$.

The diffusion mechanism for an infinite plane can be expressed in term of the microscopic mass balance:

$\frac{\mathrm{dC}}{\mathrm{dt}}=\mathrm{D}_{\mathrm{m}} \frac{\mathrm{d}^{2} \mathrm{C}}{\mathrm{dx}^{2}}$

where: $\mathrm{C}$ is the GA concentration in the matrix as a whole expressed as the weight of solute per volume unit; $D_{m}$, the effective diffusion coefficient $\left(\mathrm{m}^{2} \mathrm{~s}^{-1}\right)$ and $\mathrm{t}$ time $(\mathrm{s})$.

For a non-steady state, the analytical solution for Eq. (2) has the form of a trigonometric series:

$\frac{M_{t}}{M_{\infty}}=1-\sum_{n=0}^{\infty} \frac{8}{(2 n+1)^{2} \pi^{2}} \exp \left[-\frac{(2 n+1)^{2}}{\delta^{2}} \pi^{2} D_{m} t\right]$

being, $\mathrm{M}_{\mathrm{t}}$ the total quantity of the substance that releases in time $\mathrm{t}$ and $\mathrm{M}_{\infty}$ the corresponding quantity at an infinite time. This is an approximation which holds for the release of the first $60 \%$ of cumulative release.
At very short times, it is possible to consider the solution for a semiinfinite medium as follows:

$\frac{\mathrm{M}_{\mathrm{t}}}{\mathrm{M}_{\infty}}=4 \sqrt{\frac{\mathrm{D}_{\mathrm{m}} \mathrm{t}}{\pi \delta^{2}}}$

\subsection{Antimicrobial capacity}

Batch cultures of typical food pathogens such as Gram-positive bacteria Staphylococcus aureus ATCC 25923 and Gram-negative bacteria (Escherichia coli ATCC 25922 and Salmonella spp.) were obtained from Microbiology Chair (National University of La Plata, Argentina). Candida vinaria was obtained from yeast collection of Microbiology Laboratory of the Center for Research and Technical Assistance to Agri-food Industry (CIATI). The procedure of isolation and identification of Salmonella spp. was performed according to AOAC 46-115 [24]. Positive colonies were confirmed by the API 20E kit (Biomerieux, France).

Candida vinaria was growth in broth malt containing malt extract (1\%, Biokar, France), yeast extract (2\%, Biokar, France) and glucose (1\%, Merck, Germany). S. aureus, E. coli, and Salmonella spp. were grown in Mueller-Hinton broth (Merck, Germany).

All microorganisms tested were incubated at $37{ }^{\circ} \mathrm{C}$ overnight until providing concentrations of $10^{8} \mathrm{CFU} \mathrm{mL}^{-1}$ determined by optical density (OD) of the suspension. Then, dilutions 1:10 were prepared from these inocula with sterile $0.1 \%$ of peptone water (Oxoid) to obtain concentrations of $10^{7} \mathrm{CFU} \mathrm{mL} \mathrm{m}^{-1}$. Inoculation was performed by incorporation of $100 \mu \mathrm{L}$ suspension onto the surface and carefully spreading the liquid over the media using the spread plate technique. The isolates were tested for susceptibility to the films by the disc diffusion method.

In order to analyze the antimicrobial capacity of $\mathrm{Ch}, \mathrm{ChGA}$ and nanocomposite matrices $\left(\mathrm{ChN}_{\mathrm{A}}, \mathrm{ChN}_{\mathrm{B}}\right)$, the film samples were cut into discs of $1.5 \mathrm{~cm}$ diameter and three discs placed on the surface of inoculated agar plate by using sterile tweezers. Afterward, the plates were incubated at $37^{\circ} \mathrm{C}$ and inhibition zones were measured. The diameters of inhibitory zone adjacent to the film discs as well as the contact area of these with the media were measured. The zone of inhibition assay on solid media was used for determining the antimicrobial effects of the films against E. coli, Salmonella spp., S. aureus, and Candida vinaria.

The tests were performed in triplicate to ensure reproducibility of the results. Visual observations were conducted in all cases, photographs were taken, and inhibitory zones of the films were observed after 24,48 , and $72 \mathrm{~h}$ of incubation at $37{ }^{\circ} \mathrm{C}$. Photo analysis was performed using the Image J package.

\subsection{Statistical analysis}

For the statistical analysis of the results, the SYSTAT software (SYSTAT Inc., Evanston, IL, USA) was applied. Analysis of variance was carried out by means of ANOVA procedures. Fisher LSD test was performed for simultaneous pairwise comparisons. F-tests and differences in means were considered statistically significant when $p<0.05$.

The principal component analysis (PCA) was conducted on mean values using Infostat v2009 software (Córdoba, Argentina).

\section{Results and discussion}

\subsection{Characterization of nanoparticles}

Chitosan's ability to gel on contact with TPP relies on the formation of inter- and intramolecular crosslinking mediated by these counterions. Specifically, Ch nanoparticles were obtained as a result of molecular linkages formed between chitosan amino group and TPP phosphates. The concentration of $\mathrm{Ch}$, active compound $\left(\mathrm{mg}_{\mathrm{GA}} / \mathrm{g}_{\mathrm{Ch}}\right)$, and Ch:TPP ratio used to obtain the nanoparticle suspensions, as well as zeta potential 
Table 1

Zeta potential ( $\mathrm{ZP}, \mathrm{mV})$ and nanoparticle diameters $(\mathrm{nm})$ from $\mathrm{N}_{\mathrm{A}}$ and $\mathrm{N}_{\mathrm{B}}$ suspensions. Variables were: chitosan concentration $(\mathrm{w} / \mathrm{w})$, chitosan:tripolyphosphate ratio (Ch:TPP) and gallic acid concentration expressed as $\mathrm{mg}_{\mathrm{GA}} / \mathrm{g}_{\mathrm{Ch}}$.

\begin{tabular}{llllll}
\hline Suspension & Ch $(\%)$ & Ch:TPP & GA $(\mathrm{mg} / \mathrm{gCh})$ & $\mathrm{ZP}(\mathrm{mV})^{*}$ & Diameter $(\mathrm{nm})$ \\
\hline $\mathrm{N}_{\mathrm{A}}$ & 0.75 & 5 & 50 & $46.6(3.2)^{\mathrm{b}}$ & $453.1(30.0)^{\mathrm{b}}$ \\
$\mathrm{N}_{\mathrm{B}}$ & 0.75 & 3 & 50 & $27.7(1.2)^{\mathrm{a}}$ & $140.3(7.1)^{\mathrm{a}}$
\end{tabular}

*Different letters in the same column indicate significant differences $(p<0.05)$ between samples.

and size values of the formed nanoparticles are shown in Table 1. As can be seen, the lower the Ch:TPP ratio, the smaller the particle diameter and the lower the ZP were [16].

The ability of the ionic gelation process to form chitosan nanoparticles loaded with gallic acid was assessed by ATR-FTIR. Measurements were carried out to identify the possible biomolecules responsible for Ch nanoparticle formation. The spectral analysis of chitosan nanoparticles $\mathrm{N}_{\mathrm{A}}, \mathrm{N}_{\mathrm{AE}}, \mathrm{N}_{\mathrm{B}}$, and $\mathrm{N}_{\mathrm{BE}}$ are depicted in Fig. 1. All the spectra exhibited the absorption bands at $1637 \mathrm{~cm}^{-1}(\mathrm{C}=\mathrm{O}$ stretching in amide group, amide I vibration), $1538 \mathrm{~cm}^{-1}$ ( $-\mathrm{NH}_{2}$ bending in non-acetylated 2aminoglucose primary amine) and $1377 \mathrm{~cm}^{-1}$ (C-O stretching of primary alcohol groups) (Fig. 1). The absorption peak at $1150 \mathrm{~cm}^{-1}$ (antisymmetric stretching of the $\mathrm{C}-\mathrm{O}-\mathrm{C}$-glycosidic linkage between chitosan monomers) and $1018 \mathrm{~cm}^{-1}$ (skeletal vibrations involving the $\mathrm{C}-\mathrm{O}$ stretching) characteristic of the chitosan saccharide structure were observed [18].

On the other hand, the loaded suspension spectra $\left(\mathrm{N}_{\mathrm{A}}\right.$ and $\left.\mathrm{N}_{\mathrm{B}}\right)$ exhibited interactions among $\mathrm{Ch}, \mathrm{GA}$ and the crosslinking agent TPP (Fig. 1). The decrease of the band observed in the region of amide II is explained by the interactions with TPP, responsible for the Ch separation from the solution in the form of nanoparticles and the reduction of Ch solubility. The crosslinked chitosan also showed a reduced peak at $1150 \mathrm{~cm}^{-1}$ attributed to the bend $\mathrm{P}=0$ [25].

Other bands attributed to the presence of TPP were located at $1096 \mathrm{~cm}^{-1}$ (symmetric and antisymmetric stretching vibrations in the $\mathrm{PO}_{3}$ group) and $892 \mathrm{~cm}^{-1}$ (antisymmetric stretching of the P-O-P bridge) [26]. The higher the concentration of TPP the greater the differences observed between $\mathrm{N}_{\mathrm{B}}$ and $\mathrm{N}_{\mathrm{A}}$, or $\mathrm{N}_{\mathrm{BE}}$ and $\mathrm{N}_{\mathrm{AE}}$ nanoparticles.

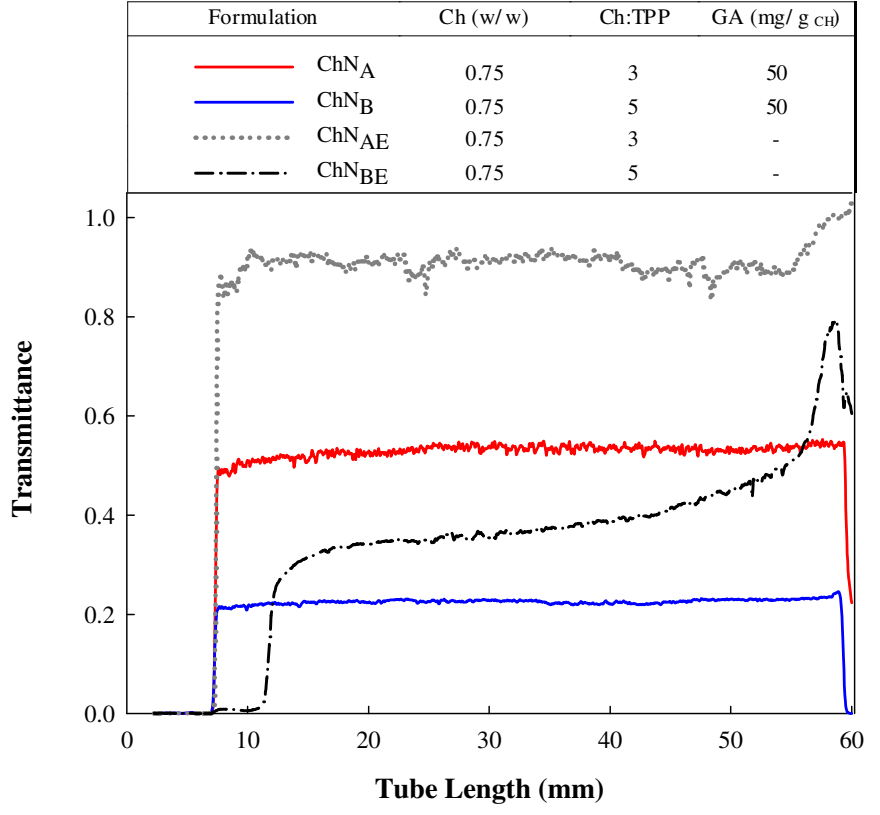

Fig. 2. Transmittance profiles of nanoparticle suspensions without $\left(\mathrm{N}_{\mathrm{AE}}, \mathrm{N}_{\mathrm{BE}}\right)$ and with gallic acid $\left(\mathrm{N}_{\mathrm{A}}, \mathrm{N}_{\mathrm{B}}\right)$ obtained by the QuickScan method. Table insert shows the composition of the suspensions.

The spectral region $2800-3500 \mathrm{~cm}^{-1}$ also showed difference among empty and GA loaded nanoparticles (Insert in Fig. 1). This region becomes more attenuated, indicating that $\mathrm{H}$-bond interactions with Ch-GA were increased in the presence of GA.

The suspensions of nanoparticles were also studied from the stability point of view by means of the QuickScan methodology, which exposed the role played by the GA in strengthening the stability of the system. As can be seen in Fig. 2, samples prepared without GA produced more transparent suspensions displaying higher transmittance value than those containing active compounds. According to Alonso et al. [27], the GA may behave like a notable non-ionic surfactant since its

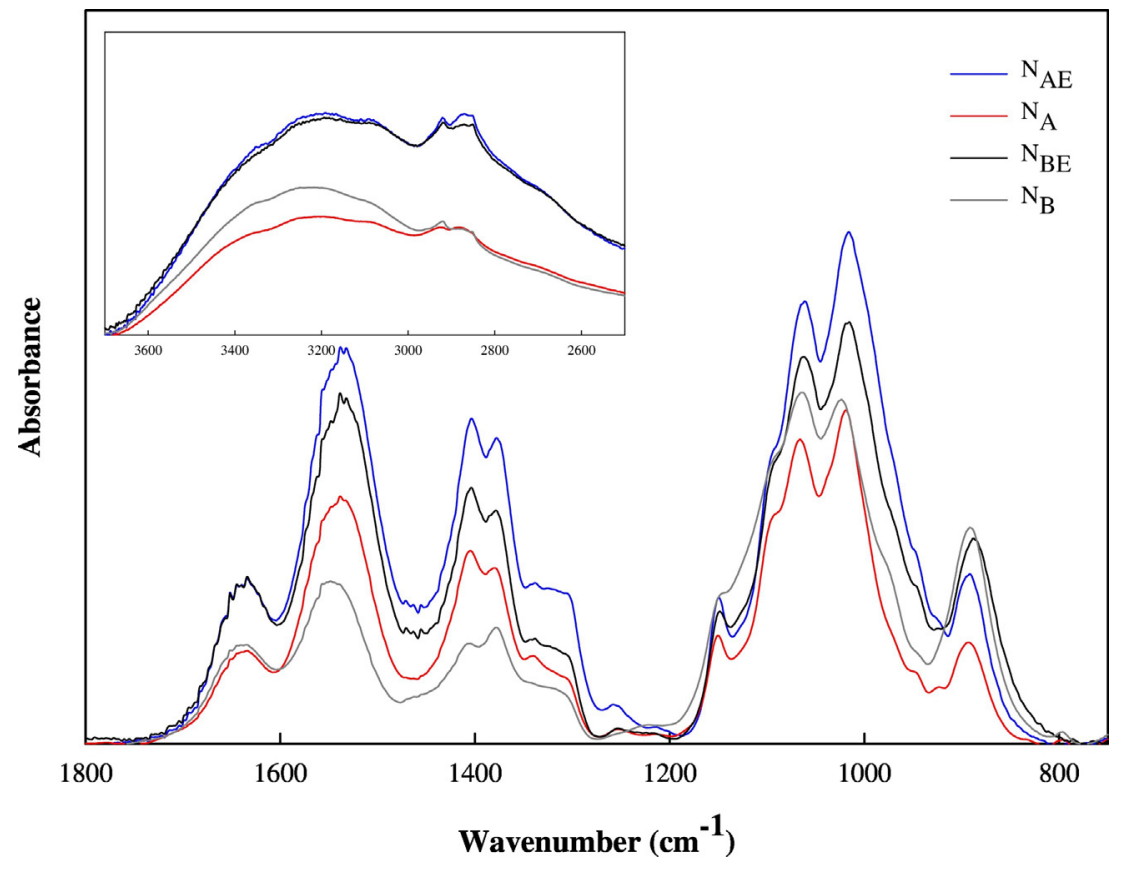

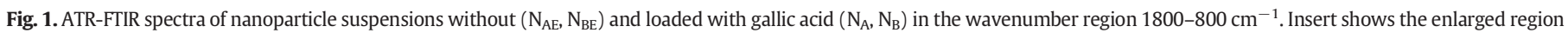
$3600-2600 \mathrm{~cm}^{-1}$. 
surfactant effectiveness is in the range of other relevant commercial non-ionic surfactants by further increasing the dispersibility and accordingly the surface area of nanoparticles. This explanation was correlated with the lower transmittance value obtained (Fig. 2). Although both suspensions $\mathrm{N}_{\mathrm{A}}$ and $\mathrm{N}_{\mathrm{B}}$ demonstrated to be stable, it is worth noting that the higher the ratio Ch:TPP of the suspension and the greater the nanoparticle size, the higher the transmittance value was (Fig. 2). Similar results were obtained by Kim et al. [28]. The authors found that the transmittance of the dispersion of carbon nanotubes with surfactants was very low and remained almost constant. On the other hand, the transmittance of the dispersion without a surfactant increased dramatically indicating that aggregation occurred. In addition, the aqueous dispersions with surfactants were more stable than that without a surfactant.

Additionally, Hong et al. [29], studied the stability of the encapsulated carbon nanotubes by poly(4-vinylpyridine) which was improved in alcoholic medium due to the chemical affinity of P4VP with alcohol.

\subsection{Water-resistive properties}

Considering single $(\mathrm{Ch})$, active matrix (ChGA) and nanocomposite active films $\left(\mathrm{ChN}_{\mathrm{A}}\right.$ and $\mathrm{ChN}_{\mathrm{B}}$ ), all of them were uniform and homogeneous with thicknesses of about $70 \mu \mathrm{m}$ on average. Table 2 shows water-resistive and optical properties of the films.

As can be seen in Table 2, moisture content presented the lowest value for Ch films. Meanwhile, $\mathrm{ChN}_{\mathrm{A}}$ and $\mathrm{ChN}_{\mathrm{B}}$ showed the highest values but the difference between them was no significant $(p>0.05)$. The increase of moisture content in the presence of GA could be attributed to higher sites available for water sorption in the polymeric matrix due to an increase in the number of hydrophilic molecules.

Taking the water vapor permeability into account, chitosan films exhibited a value of $1.3 \times 10^{-10} \mathrm{~g} \mathrm{~m}^{-1} \mathrm{~s}^{-1} \mathrm{~Pa}^{-1}$, which was not significantly different than those obtained for ChGA and nanocomposites $(p>0.05)$. This fact could be explained probably owing to the small amount of both GA and nanoparticles added to the Ch matrix.

The swelling of Ch films in water was $880 \%$ and underwent a decrease after the direct addition of GA which interacted with $\mathrm{Ch}$. In this way, other authors also found that the inclusion of active compounds such as tannic and ferulic acids induce crosslinking reactions, reducing the swelling capacity and the solubility of the matrix [30,31]. With the addition of nanoparticles, the swelling ability of the samples was reduced owing to an additional crosslinking process. Although ionic interactions between the negative charges of the crosslinker (TPP) and positively charged groups of $\mathrm{Ch}$ were the main interactions occurring within the network, the simultaneous presence of TPP and GA contributed to closer interactions. The network had a lower hydrodynamic free volume to accommodate the solvent molecules, thereby inducing a slight swelling of chitosan-TPP matrices obtaining a reduction by $29 \%$ compared to control film $(p<0.05)$ (Table 2$)$. These findings are in agreement with those found by Parize et al. [32]. These authors suggested that the crosslinking process decreases the degree of matrix swelling.

Table 2

Water-resistive and optical properties of formulated Ch-based films.

\begin{tabular}{lllll}
\hline Film properties $^{*}$ & Ch & ChGA & ChN $_{\mathrm{A}}$ & ChN $_{\mathrm{B}}$ \\
\hline Moisture content (\%) & $14.3(0.01)^{\mathrm{a}}$ & $19.7(0.2)^{\mathrm{a}, \mathrm{b}}$ & $21.7(1.7)^{\mathrm{a}, \mathrm{b}}$ & $23.7(3.5)^{\mathrm{b}}$ \\
Swelling capacity (\%) $^{\mathrm{a}}$ & $920.7(39.9)^{\mathrm{c}}$ & $717.8(2.4)^{\mathrm{b}}$ & $372.8(15.3)^{\mathrm{a}}$ & $348.4(30.9)^{\mathrm{a}}$ \\
Solubility (\%) & $57.1(2.4)^{\mathrm{c}}$ & $14.9(1.3)^{\mathrm{a}}$ & $16.7(0.02)^{\mathrm{a}}$ & $17.4(0.3)^{\mathrm{a}}$ \\
$\left.\mathrm{WVP} \times 10^{10}\right)$ & $1.3(0.1)^{\mathrm{a}}$ & $1.1(0.1)^{\mathrm{a}}$ & $1.3(0.004)^{\mathrm{a}}$ & $1.2(0.1)^{\mathrm{a}}$ \\
Transparency & $18.6(0.3)^{\mathrm{a}}$ & $26.7(0.8)^{\mathrm{c}}$ & $16.0(0.3)^{\mathrm{a}}$ & $21.0(0.6)^{\mathrm{b}}$ \\
Opacity & $24.3(0.08)^{\mathrm{a}}$ & $37.1(3.7)^{\mathrm{c}}$ & $32.4(3.7)^{\mathrm{b}}$ & $32.0(0.7)^{\mathrm{b}}$ \\
UV barrier & $77.2(2.7)^{\mathrm{a}}$ & $159.9(8.4)^{\mathrm{d}}$ & $129.5(1.6)^{\mathrm{c}}$ & $113.5(8.8)^{\mathrm{b}}$ \\
\hline
\end{tabular}

* Different letters in the same row indicate significant differences $(p<0.05)$ between samples.
Mi et al. [33] found that the ionic-crosslinked chain of chitosan-TPP does not dissociate at neutral $\mathrm{pH}$, and hence the swelling of the nanocomposites would be mainly attributed to the hydration or ionization of unbound $-\mathrm{NH}_{2}$ groups but not to the scission of the ionic-crosslinked chain.

Although the incorporation of nanoparticles implied the addition of TPP and hence a lower amount of $\mathrm{Ch}$ free, the solubility did not significantly differ from that obtained by means of the direct inclusion of GA $(p>0.05)$ (Table 2).

\subsection{Optical properties}

The study of the UV light absorption capacity of the biodegradable films is relevant to determine their possible applications for food packaging [34].

The UV-vis absorption spectra of gallic acid and film-forming solutions with and without nanoparticle suspensions were recorded (data not shown). The absorption peak of the active compound in solution either incorporated directly or encapsulated into Ch solutions was observed at $269 \mathrm{~nm}$. Comparing the spectra of solutions containing nanoparticles, $\mathrm{N}_{\mathrm{A}}$ and $\mathrm{N}_{\mathrm{B}}$, with sizes of 453.1 and $140.3 \mathrm{~nm}$, respectively, it can be inferred that the size influenced on the absorbance. The higher the diameter of the particles, the higher the absorbance values were.

On the other hand, all films exhibited barrier UV properties since a characteristic peak in the range $265-340 \mathrm{~nm}$ was observed (Fig. 3). Although Ch films depicted a barely noticeable peak at $265 \mathrm{~nm}$ [35] they had a lower capacity to absorb UV light than matrices containing GA. Thereby, the presence of GA enhanced the light barrier properties of Ch films.

Considering the spectra of both, the chitosan solution (film forming solution) and solid state (chitosan-based films), the displacement of the absorption peak from 265 to $278 \mathrm{~nm}$, respectively, in the presence of GA or nanoparticles functionalized with this compound, was observed. The most plausible explanation was the crosslinking interaction of the gallic acid and $\mathrm{Ch}$ molecules induced by the drying process [36].

Analyzing other optical properties, Ch films exhibited the highest transparency (that is, the lowest value). The addition of GA decreased the transparency in relation to $\mathrm{Ch}$ matrix and showed a significant effect on the opacity, which increased by $26 \%$ concerning the Ch value (Table 2). Similar results were reported by Siripatrawan and Harte [37] for Ch films functionalized with an aqueous green tea extract. Furthermore, nanocomposites were less opaque (and more transparent) than ChGA matrices. Taking particle size into account, nanocomposite film opacity was higher for $\mathrm{ChN}_{\mathrm{A}}$ than $\mathrm{ChN}_{\mathrm{B}}$. According to Niroomand

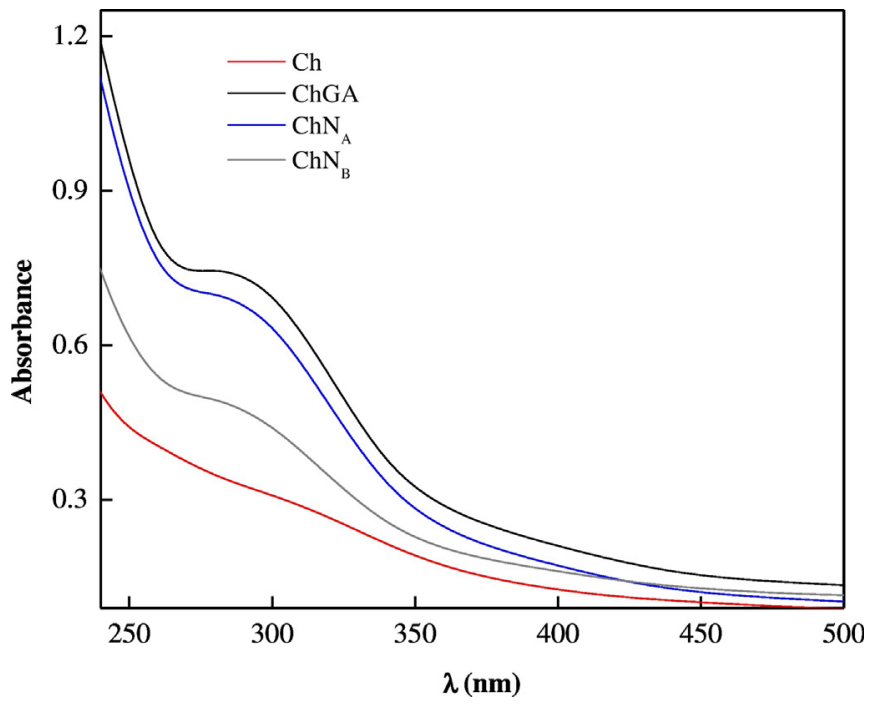

Fig. 3. UV-vis light absorption spectra of $\mathrm{Ch}, \mathrm{ChGA}$, and nanocomposites $\left(\mathrm{ChN}_{\mathrm{A}}\right.$ and $\left.\mathrm{ChN}_{\mathrm{B}}\right)$. 
et al. [38], when light passes through the film, a considerably lower amount of light is transmitted through the matrix containing nanoparticles, which results in a higher opacity value.

\subsection{Analysis by PCA}

Fig. 4 shows PCA biplots used to visualize and summarize the relationships between the samples and the attributes associated with optical and water-resistive properties. Inspecting the contributions, biplot revealed that the variability explained by the first component PC1 was $64.9 \%$ and the second PC2 30.1\%, respectively.

The PCA correlation plot shows the clustering of the nanocomposites in relation to $\mathrm{Ch}$ and ChGA films. Nanocomposites were separated from Ch and ChGA matrices and the separation was carried out along PC2. Samples formulated with nanoparticles presented the most negative values of PC2, ChGA was located on the right-side of the chart whereas $\mathrm{Ch}$ control had negative values. The control $\mathrm{Ch}$ was better interpreted in terms of solubility and swelling, ChGA was associated principally with transparency, opacity and UV barrier. Although $\mathrm{ChN}_{\mathrm{A}}$ and $\mathrm{ChN}_{\mathrm{B}}$ showed the highest values of moisture they were far away from swelling and solubility.

\subsection{Mechanical properties}

The mechanical responses of the studied films carried out by a DMA under uniaxial tension were evaluated through stress-strain tests. Fig. 5a also depicts the non-linear model (Eq. (1)) used to estimate the elastic modulus Ec, which fitted the all experimental data satisfactorily with $r^{2}>0.980$. As can be observed in Table insert in Fig. 5a, ChGA films exhibited the highest Ec and stress values.

Analyzing the film behavior, the tensile test results suggested that the mechanical properties of the ChGA films were superior to those of neat chitosan due to the reinforcement provided by the crosslinker throughout the biopolymeric matrix. The addition of GA led to an increase by $52 \%$ of the stress and a reduction by $17 \%$ of the strain $(p<0.05)$ in relation to Ch films, as a consequence of the formation of intermolecular hydrogen bonding between $\mathrm{Ch}$ backbone and the $\mathrm{OH}^{-}$of gallic acid [39], that restricts the matrix motion. A similar trend was reported by Orliac et al. [40] working on thermo-moulded films produced from sunflower protein.

In the case of $\mathrm{ChN}_{\mathrm{A}}$, maximum values reached were $30 \mathrm{MPa}$ and $2.8 \%$, whereas for $\mathrm{ChN}_{\mathrm{B}}$ films, the strain maintained values practically unaltered and stress had a non-significant increase $(p>0.05)$ in relation to Ch films.

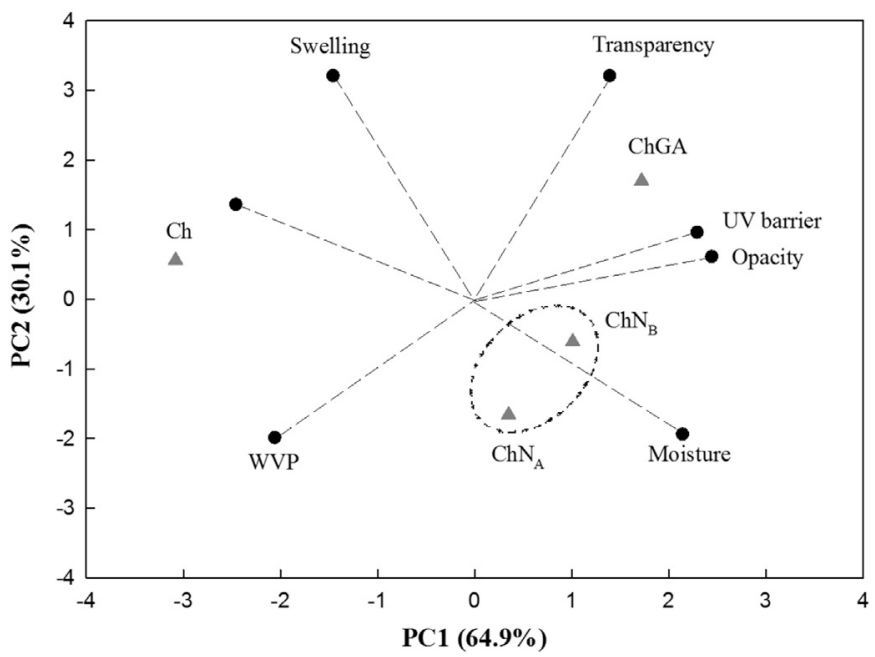

Fig. 4. PCA biplots summarizing the relationships between the samples ( $\mathrm{Ch}, \mathrm{ChGA}, \mathrm{ChN}_{\mathrm{A}}$ and $\left(\mathrm{ChN}_{\mathrm{B}}\right.$ ) and the attributes associated with optical and water-resistive properties.
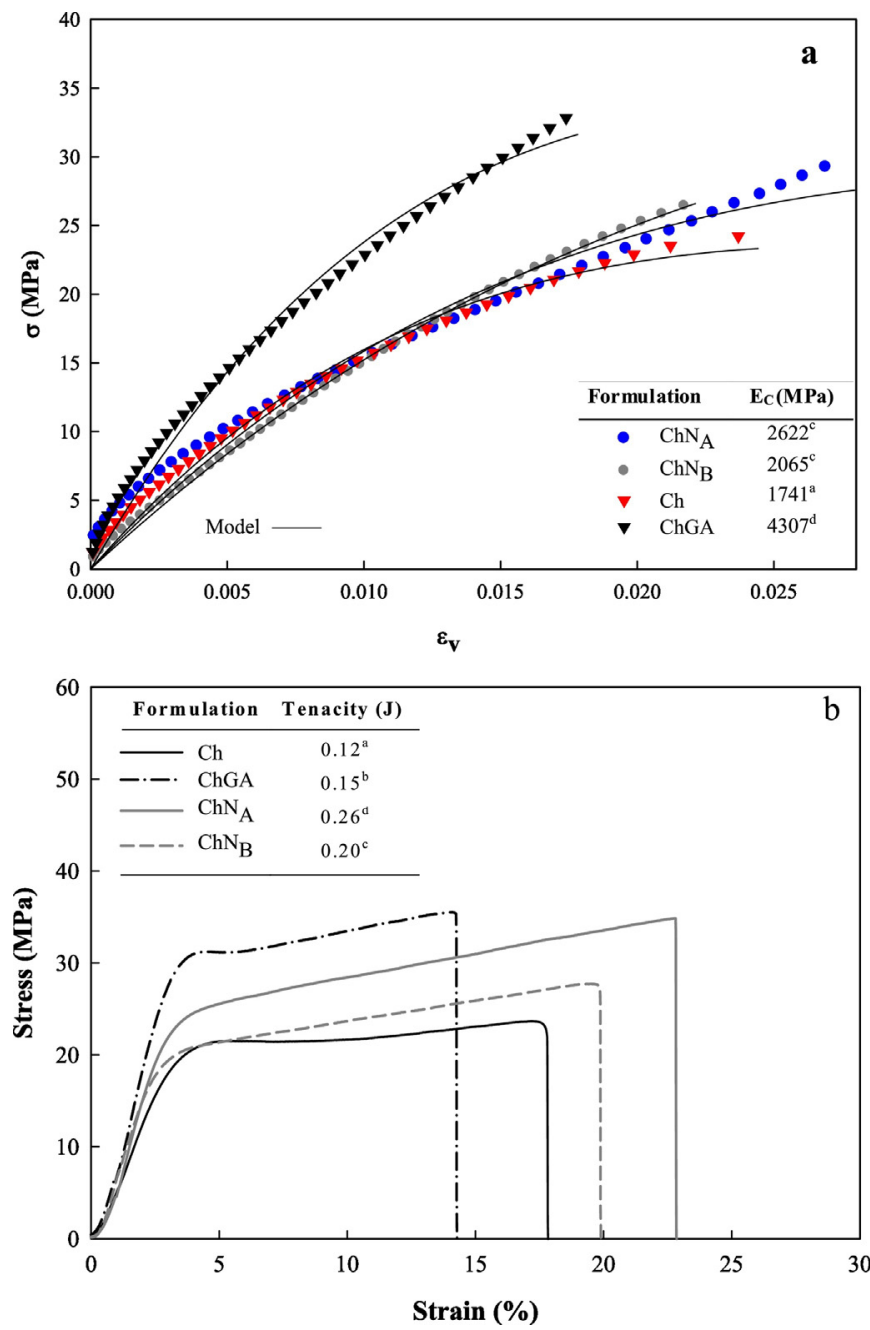

Fig. 5. Tensile stress-strain behavior of $\mathrm{Ch}, \mathrm{ChGA}$, and nanocomposites $\left(\mathrm{ChN}_{\mathrm{A}}\right.$ and $\left.\mathrm{ChN}_{\mathrm{B}}\right)$ determined by a) quasi-static method and b) texture analyzer. Continuous lines indicate data fitted by means of Eq. (1).

At this point, it would be worth bearing in mind that the particles crosslinked with TPP represented only a moiety of the total system since the majority of the support matrix was formed by Ch noncrosslinked. That is, although TPP played a role as a crosslinker, especially concerning $\mathrm{ChN}_{\mathrm{A}}$ with a Ch:TPP ratio equal to $5(<\mathrm{TPP})$, the effect on the structure were less than expected and they resulted in a higher elongation. The decrease of stress and the increase of the strain would prove that nanoparticles have a plasticizing effect for the film. This indicates that incorporating nanoparticles into the films resulted in strong interactions between the filler and the matrix.

As claimed by de Moura et al. [13], nanoparticles induce the collapse of the pores occupying the empty spaces of the active matrix and thereby improving the mechanical properties.

On the other hand, Fig. 5b shows the mechanical patterns of assays carried out on a texture analyzer. The obtained findings were similar to those evaluated by uniaxial tension tests.

Force-deformation curves obtained for $\mathrm{Ch}$ films followed a pattern characteristic of a ductile material. When nanoparticles were incorporated, the Ch matrix became a much more ductile material, as depicted in Fig.5b. Both, the increase in elongation and stress values of the materials functionalized with nanoparticles evidenced improvements in the tenacity of the films demonstrating the reinforcing effects of the particles, as can be seen in Table insert in Fig. 5b. According to Bhattacharya [41], the nanoparticle dispersion and the bonding between the filler and the polymer are essential to allow transferring the external stress 
applied to the composite to the nanofillers. Hence, nanoparticles are often functionalized enhancing their dispersibility and allowing their interactions with polymers.

SEM micrographs of matrixes submitted to traction assays show the cross-section of the strained Ch sample which was soft and smooth as can be seen in Fig. 6a. The examination of the micrograph provides an insight into the highly stressed regions where tiny flaws grew causing the failed of the material under the application of a tension. The matrix appears aligned in the direction of the applied force.

Taking into account ChGA films, the cross-section was rough, tear in a longitudinal direction to the stress. This observation was in accordance with the higher stiffness and low stretching of the material (Fig. 6b).

The ductility nature of the Ch matrix was improved by the addition of active nanoparticles. The micrographs give reliable insights on the homogeneous dispersion of the nanoparticles in the chitosan matrix (Fig. 6c). The fractured nanocomposites showed a high fracture strength and toughness were a result of good filler-to-matrix adhesion and dispersion of nanoparticles in a continuous phase of chitosan which acts as a binder. This result could be attributed to the structural affinity between the phases.

\subsection{X-ray studies}

It is known that chitosan is a semicrystalline polymer due to its strong intramolecular hydrogen bonds on the backbone, and it also has a rigid amorphous phase because of its heterocyclic units [42]. As can be seen in Fig. 7, Ch films exhibited peaks at $2 \theta=8.2,11.2,18.1$, and $23.0^{\circ}$. The morphological studies reflected the looseness in chain packing after introducing GA into the chitosan chains and a different pattern was developed. The reflection located at $2 \theta=23^{\circ}$ became stronger because of the presence of a sharp peak in the GA diffraction XRD spectrum, the peak at $11.2^{\circ}$ underwent a shift toward $11.6^{\circ}$, and the one at $8.2^{\circ}$ practically disappeared. This is because the addition of

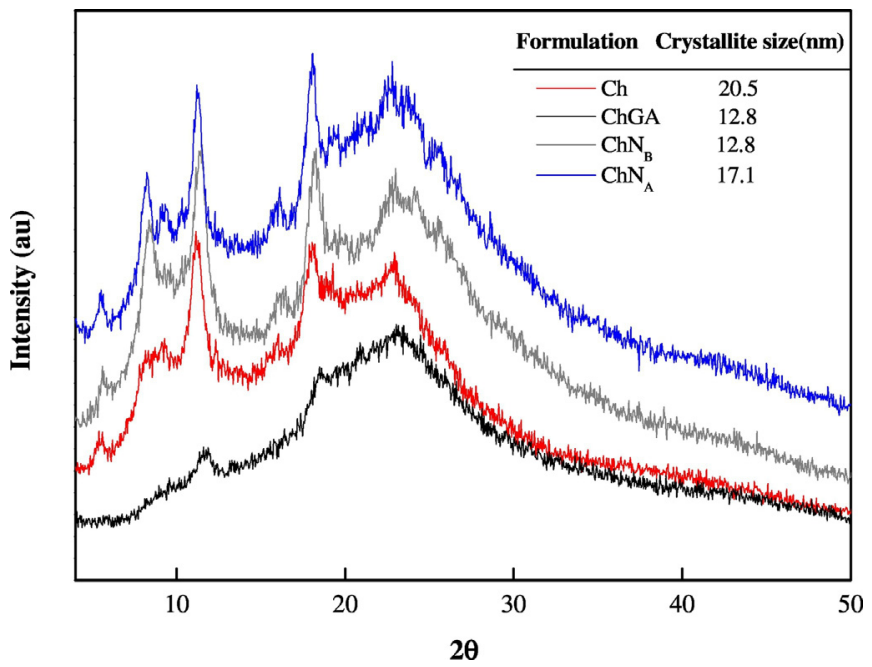

Fig. 7. X-ray diffractograms of $\mathrm{Ch}, \mathrm{ChGA}$, and nanocomposites $\left(\mathrm{ChN}_{\mathrm{A}}\right.$ and $\left.\mathrm{ChN}_{\mathrm{B}}\right)$.

GA would interrupt the intermolecular hydrogen bonding in Ch crystals, allowing Ch molecules to form more interaction with the active compound [43].

On the other hand, the inclusion of functionalized particles led to that the intensity of the reflections located at 8.7 and $11.7^{\circ}$ to be comparable (Fig. 7). Although the patterns of both nanocomposites were similar, the peaks of $\mathrm{ChN}_{\mathrm{B}}$ appeared less sharp. These findings suggest that the inclusion of nanoparticles did not change the structure of the matrix. According to Azizi et al. [44], the fact of there was neither new peaks nor peak shifts compared with $\mathrm{Ch}$ pattern would be consistent with the coexistence of two phases (polymer and nanoparticles).
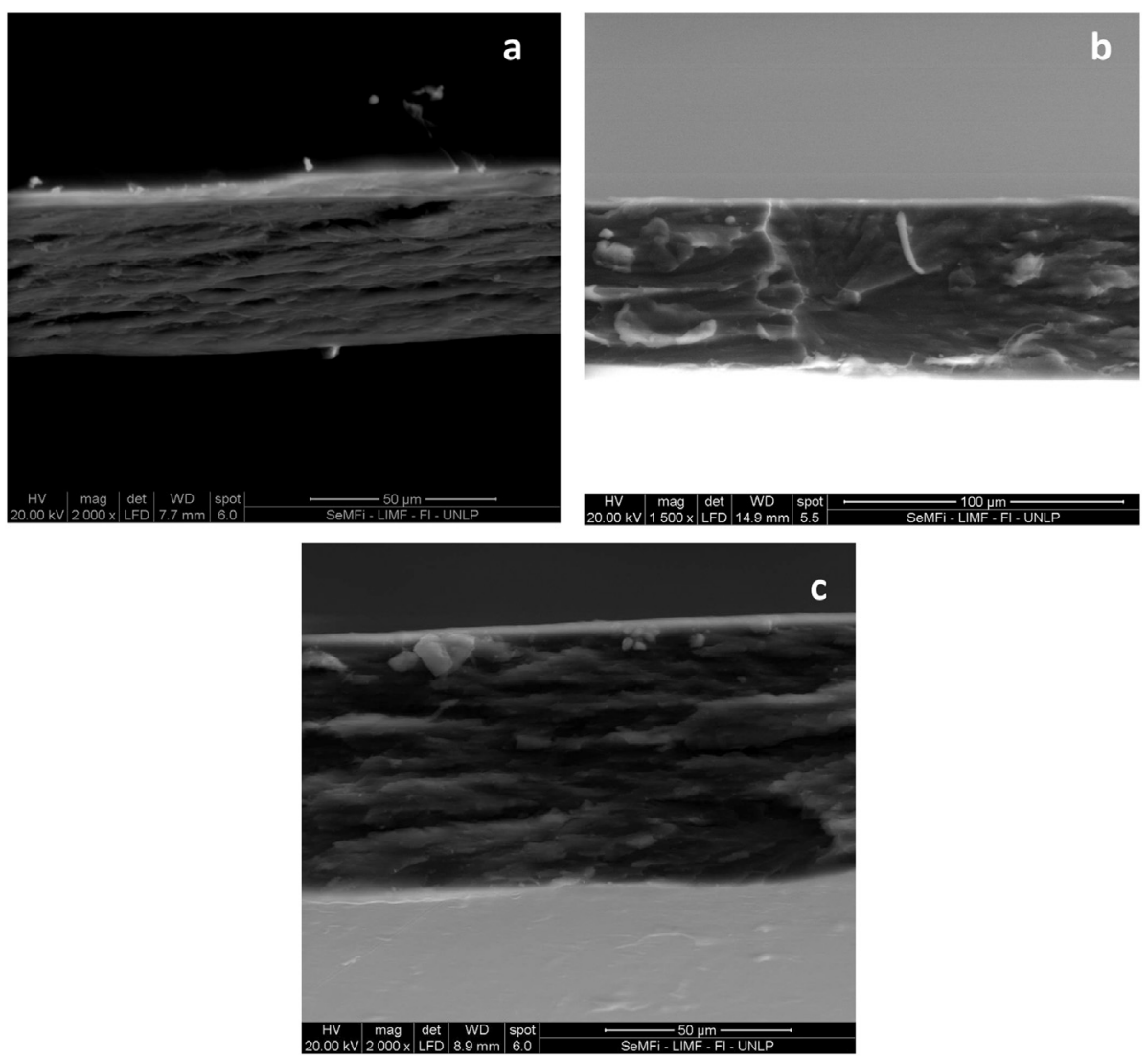

Fig. 6. Cross-section SEM micrographs of samples after being submitted to tensile fracture test: (a) Ch, (b) ChGA, and (c) ChN $\mathrm{A}_{\mathrm{A}}$. Scale bars are indicated in the images. 
The average crystallite size was calculated from XRD peak located at $18^{\circ}$ based on the Debye-Scherrer equation $[45,46]$ :

$\mathrm{D}=\frac{\mathrm{K} \lambda}{\beta \cos \theta}$

where $\beta$ is the integral half width, $K$ is the Scherrer constant ( 0.90$)$, $\lambda$ is the wavelength of the incident $X-\operatorname{ray}(\lambda=0.1540 \mathrm{~nm}), D$ is the crystallite size, $\theta$ is the Bragg diffraction angle in degrees, and $\beta$ is the full width at half maximum intensity in radians.

The diffraction peak corresponding to the lattice plane (311) at $2 \theta=18^{\circ}$ was used for calculation because this peak is well resolved and does not show any interferences (Table insert in Fig. 7).

The average crystallite size calculated for $\mathrm{Ch}$ was about $20 \mathrm{~nm}$. The crystallite size is assumed to be the size of a coherently diffracting domain and it is not necessarily the same as particle size.

The decrease in crystallite size suggests that strong interactions occurred among Ch, TPP and GA which resulted in a more amorphous structure. This result was mainly due to the strong intermolecular hydrogen bonding interaction occurred among these three components [47].

According to Sujima-Anbu et al. [48], chitosan nanoparticles consist of a network structure of interpenetrating chains crosslinked to each other by TPP. Additionally, they explained that XRD spectra exhibited a disorder in chain alignment in the nanoparticles loaded with active compound after crosslinking due to the change in the chitosan structure.

\subsection{SEM analysis}

From the microscopic point of view, Ch films showed smooth and homogeneous surfaces and with good structural integrity (Fig. 8a). While the addition of GA did not substantially modify the microstructure of neat chitosan matrix (Fig. 8b), the cross-section of nanocomposites showed clearly the nanoparticles distributed homogeneously without aggregation suggesting compatibility with the $\mathrm{Ch}$ matrix (Fig. 8c). Undoubtedly, the incorporation of nanoparticles produced changes in the microstructure of the films leading to form a continuous network where the nanoparticles act as filler (Fig. 8c and d). These results are consistent with the findings of Teodoro et al. [49] and Bhattacharya [41], who reported that fillers dispersed more homogenously improve the interactions with the matrix, and thus caused major adhesion between the nanoparticles and the continuous Ch phase. This fact would be related to the obtained mechanical properties.

\subsection{Diffusion experiments}

As described, the release of GA from Ch-based matrices was investigated by the total immersion method in the release medium.

In order to determine the mechanism controlling the GA release and compare the relative delivery velocity among the different matrices, profile data were fitted with the semiempirical equation proposed by Korsmeyer-Peppas [50]

$\frac{\mathrm{M}_{\mathrm{t}}}{\mathrm{M}_{\infty}}=\mathrm{F}_{\mathrm{T}}=\mathrm{k} \times \mathrm{t}^{\mathrm{n}}$

where $M_{t} / M_{\infty}$ is the fraction released of active compound at time $t$, $k$ is a constant and $\mathrm{n}$ is a parameter representative of the mechanism of transference of the active agent.

Gompertz [51] and Gallagher-Corrigan models [52] were also used, fitting the data by means of Sigma Plot Software 10.0.
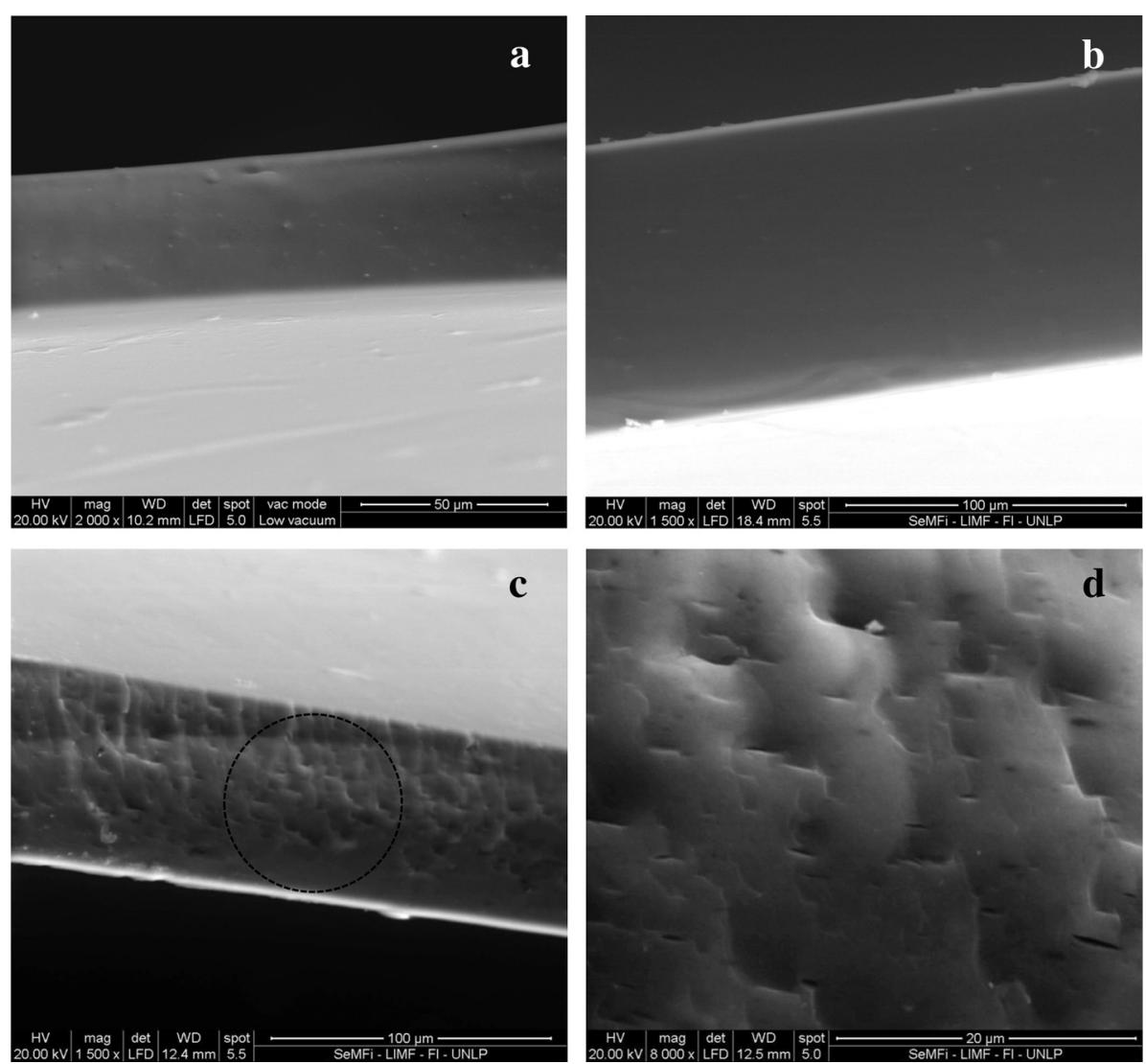

Fig. 8. Cross-section SEM micrographs of: (a) $\mathrm{Ch}$, (b) ChGA, (c) $\mathrm{ChN}_{\mathrm{A}}$, and (d) enlarged region of $\mathrm{ChN}_{\mathrm{A}}$. Scale bars are indicated in the images. 
The release can be described by a simple exponential model known as the Gompertz model expressed as follows:

$\frac{\mathrm{M}_{t}}{\mathrm{M}_{\infty}}=\exp [-\mathrm{a} \times \exp (\mathrm{b} \times \log \mathrm{t})]$

where, $\mathrm{M}_{\mathrm{t}} / \mathrm{M}_{\infty}$ is the percent of compound release at time $\mathrm{t}$, a parameter determines the undissolved proportion at $\mathrm{t}=1$ described as a location or scale parameter, $\mathrm{b}$ dissolution rate per unit of time describes a shape parameter. This model has a positive upward slope and then reaches a plateau [51].

The model of Gallagher-Corrigan estimates the total fraction of additive released at time $t\left(F_{T}\right)$, which is given by the sum of active compound transferred by surface diffusion and released caused by the degradation of the polymer matrix as follows:

$$
\begin{aligned}
\mathrm{F}_{\mathrm{T}}= & \mathrm{F}_{\mathrm{B}} \times\left(1-\exp \left(-\mathrm{K}_{\mathrm{B}} \times \mathrm{t}\right)\right)+\left(1-\mathrm{F}_{\mathrm{B}}\right) \\
& \times \frac{\exp \left(k \times \mathrm{t}-\mathrm{k} \times \mathrm{t}_{\text {MAX }}\right)}{1+\exp \left(\mathrm{k} \times \mathrm{t}-\mathrm{k} \times \mathrm{t}_{\text {MAX }}\right)}
\end{aligned}
$$

where, $\mathrm{K}_{\mathrm{B}}$ is the burst rate constant, $\mathrm{F}_{\mathrm{B}}$ the fraction of the active compound released in the burst phase, $t_{\text {MAX }}$ the time for maximum rate and $\mathrm{k}$ the rate constant of the polymer degradation phase.

In Table 3 can be seen the parameters of both Gompertz and Gallagher-Corrigan models as well as the $n$ values from the Korsmeyer-Peppas model.

The latter model fitted the experimental data $\left(r^{2}>0.958\right)$ and adequately predicted the mechanism of active compound released from the CHGA film (Eq. (6), Table 3). Since the diffusion exponent obtained was $n=0.6$, the release of the active compound would be governed by two parallel mechanisms, one type Fickian, and another corresponding to the high degree of the matrix swelling [53].

Fig. 9 shows the kinetic of release in water of GA directly included in Ch matrix. As is evident from Table 3, Gallagher-Corrigan model achieved better fitting in relation to Gompertz model $\left(r^{2}>0.965\right)$. The parameters of the first $\left(K_{B}=0.16 h^{-1}\right)$ and the second release stage $\left(\mathrm{k}=0.81 \mathrm{~h}^{-1}\right)$ for a $\mathrm{t}_{\mathrm{MAX}}$ of $24 \mathrm{~h}$, were estimated from the Eq. (8). Given that $\mathrm{k}>\mathrm{K}_{\mathrm{B}}$, the obtained release profile suggested that the polymer swelling was the main mechanism of the agent delivery.

According to Piron et al. [54], the change from a Fickian toward a non-Fickian behavior is gradual considering intermediate situations, which is consistent with a matrix that quickly swells much more than the original size.

The evaluation of the GA release from the nanocomposites gave $n$ values closer to 0.4 , inferring that the release mechanism during the first step was type-Fickian (Table 3 ). Given that $\mathrm{K}_{\mathrm{B}}>\mathrm{k}$, the release process was driven by diffusion at the initial phase release called burst stage with a slower second phase of swelling (Table 3), operating both in a cooperative way. The relation between $\mathrm{K}_{\mathrm{B}}$ and $\mathrm{k}$ in $\mathrm{ChN}_{\mathrm{A}}$ was almost three times as much as the corresponding to $\mathrm{ChN}_{\mathrm{B}}$. Although swelling did not differ significantly $(p>0.05)$ between both nanocomposites, $\mathrm{ChN}_{\mathrm{A}}$ may have a second stage faster because of the minor content of TPP and the bigger diameter of the nanoparticles. Meanwhile, $\mathrm{ChN}_{\mathrm{B}}$, with the minor size of nanoparticles could retain the active compound more strongly due to closer interactions. According to Sugita et al. [15], the release of GA through the mechanism of diffusion in nanoparticles may occur because of swelling of both reservoir and diffusion matrix. The nanoparticles absorb solvent, which causes the hydrogel to expand (swelling) enlarging its size and allowing the active compound to be delivered to the environment [15].

In both nanocomposites, the time required to reach the second stage ( $t_{\mathrm{MAX}}=26$ and $42 \mathrm{~h}$, respectively) as well as that necessary to achieve the complete release (Fig. 9) was longer than those obtained when GA was directly included in $\mathrm{Ch}$ matrix $\left(\mathrm{t}_{\mathrm{MAX}}=24 \mathrm{~h}\right)$. From these results, it can be inferred that a more controlled and continuous release was achieved with nanocomposite systems, this effect being more retarded in the case of $\mathrm{ChN}_{\mathrm{B}}$ films. Since it was one of the aims sought, this finding represents an advance from a technological perspective. Robert et al. [55] informed the presence of two steps in the release profile, obtaining a release time ranging from 60 to $480 \mathrm{~min}$ for GA microencapsulated in structures based on starch and inulin.

Using the computer program Mathcad 7 Professional (Math Soft Engineering \& Education, Inc., Cambridge, USA), the experimental diffusion coefficients of GA were determined from Eqs. (3) and (4); the obtained results are shown in Table inserted in Fig. 9.

Depending on the gallic acid inclusion strategy, the diffusion coefficients varied from $1.65 \times 10^{-14} \mathrm{~m}^{2} \mathrm{~s}^{-1}$ to $2.1 \times 10^{-14} \mathrm{~m}^{2} \mathrm{~s}^{-1}$ (Table inserted in Fig. 9). In the case of nanocomposites, the slowest process was most likely due to the reduced mobility of active compound molecules in the chitosan network. Moreover, the diffusion coefficient decreased with an increase in the crosslink density, which corresponded to nanoparticles formulated with the highest TPP content (the lowest Ch:TPP ratio) modulating the diffusion of GA from the Ch matrix.

Rivero [56] informed values of the diffusion coefficients of chitosan films with the addition of propionic, ferulic and tannic acids of 1.33 1.95 and $0.83 \times 10^{-10} \mathrm{~m}^{2} \mathrm{~s}^{-1}$, respectively. A diffusivity value of about $0.8 \times 10^{-15} \mathrm{~m}^{2} \mathrm{~s}^{-1}$ was obtained by Lopez de Dicastillo et al. [57] working on active packaging films based on ethylene vinyl alcohol copolymer (EVOH) and green tea extract.

To determine the experimental values of the dimensionless $M_{t} / M_{\infty}$, the mass that released from the matrix at a given time and the maximum amount of active compound that would be released at an infinite time were considered. In the numerical simulation, considering the semi-thickness of each sample, diffusivity values were proposed and predicted values of $\mathrm{M}_{\mathrm{t}} / \mathrm{M}_{\infty}$ were attained by means of the Eq. (3). Using an iterative procedure, diffusion coefficients were obtained minimizing the sum of both the residues and the square residues.

\subsection{Antimicrobial analysis}

The antimicrobial activities of $\mathrm{Ch}$ films and matrices containing GA (ChGA, $\mathrm{ChN}_{\mathrm{A}}$, and $\mathrm{ChN}_{\mathrm{B}}$ ) are depicted in Fig. S1 (Supporting File). The diameter of the highlight regions surrounding the films indicates the antimicrobial capacity. The percentage and diameter of inhibition area against Staphylococcus aureus ATCC 25923, Salmonella spp., Escherichia coli ATCC 25922 and Candida vinaria are shown in Table 4.

All the strains exhibited a bacteriostatic effect on the studied films, especially Candida vinaria which maintained the halos until $72 \mathrm{~h}$ after the beginning of the tests. For all films assayed, the lowest values of inhibition capacity against $S$. aureus were achieved (Table 4). Furthermore, the film showed a higher effectiveness against Salmonella spp. and E. coli compared to $S$. aureus, which could be rationalized by the structural difference of the outer membrane of Gram-positive bacteria and Gram-negative bacteria (Fig. S1 of Supporting file) [58]. The

Table 3

\begin{tabular}{|c|c|c|c|c|c|c|c|c|c|c|c|}
\hline \multirow[t]{2}{*}{ Formulation } & \multicolumn{5}{|c|}{ Gallagher-Corrigan model } & \multicolumn{4}{|c|}{ Gompertz model } & \multicolumn{2}{|c|}{ Korsmeyer-Peppas model } \\
\hline & $\mathrm{F}_{\mathrm{B}}$ & $\mathrm{k}$ & $\mathrm{K}_{\mathrm{B}}$ & $\mathrm{t}_{\mathrm{MAX}}(\mathrm{h})$ & $r^{2}$ & A & $\mathrm{K}$ & $\mathrm{y}$ & $\mathrm{r}^{2}$ & $\mathrm{n}$ & $\mathrm{r}^{2}$ \\
\hline ChGA & 0.72 & 0.81 & 0.16 & 24 & 0.990 & 0.99 & 0.15 & 6.07 & 0.988 & 0.60 & 0.987 \\
\hline $\mathrm{ChN}_{\mathrm{A}}$ & 0.17 & 0.09 & 0.74 & 26 & 0.965 & 0.86 & 0.07 & 9.88 & 0.945 & 0.40 & 0.980 \\
\hline $\mathrm{ChN}_{\mathrm{B}}$ & 0.34 & 0.12 & 0.39 & 42 & 0.968 & 1.00 & 0.04 & 18.52 & 0.901 & 0.46 & 0.959 \\
\hline
\end{tabular}

Model parameters obtained from the Gallegher-Corrigan, Gompertz and Korsmeyer-Peppas models for controlled release of gallic acid in water from ChGA, ChN $\mathrm{A}_{\mathrm{A}}$ and $\mathrm{ChN}_{\mathrm{B}}$ films. 


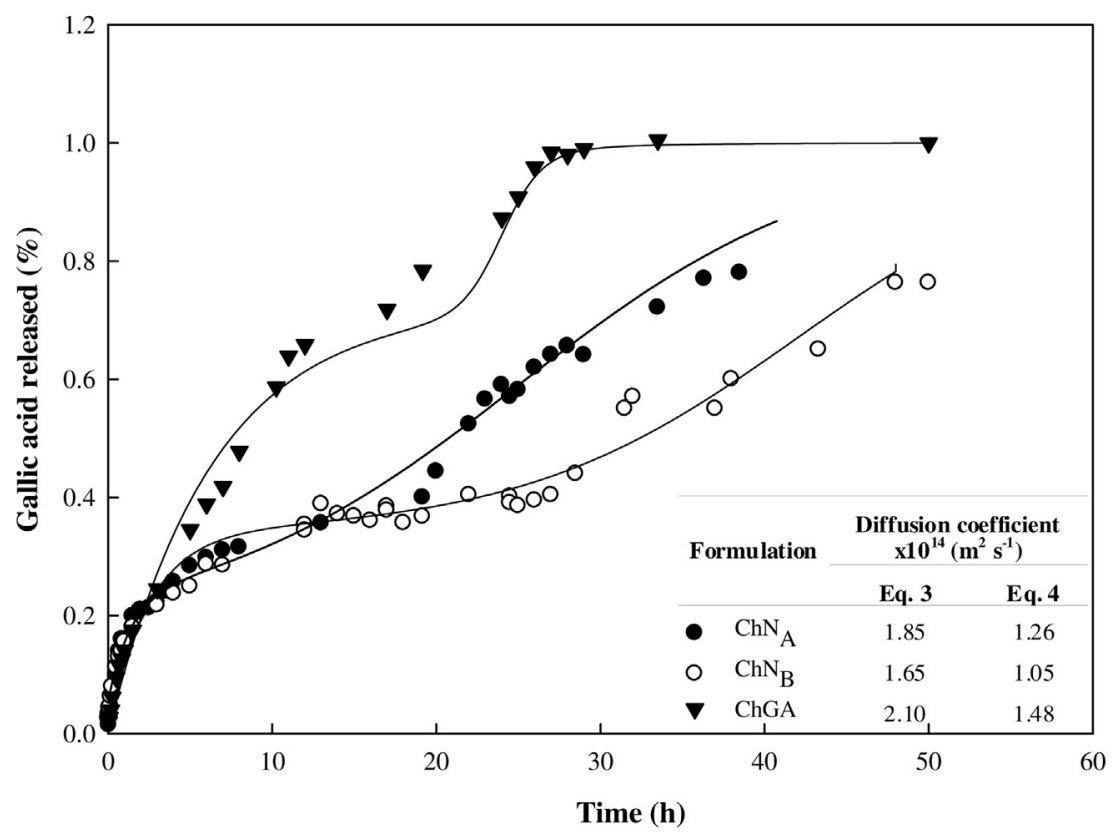

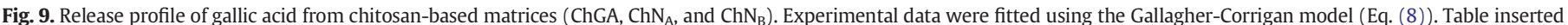
shows the diffusion coefficients obtained by means Eq. (3) and Eq. (4).

inclusion of GA and its combination with chitosan showed an improved antimicrobial effect due to the synergistic interaction. Similar results were informed by Sun et al. [10]. According to Maria Magdalane et al. $[59,60]$, the electrostatic attraction between the negatively charged bacterial cell and the positively charged of the biopolymer contributes to the improvement of the efficiency antimicrobial of materials generating a lysis of these structures, causing the loss of intracellular compounds.

The type of microorganisms and its cell membrane structure and composition take an important role in the susceptibility to active compounds. In this way, Borges et al. [61] reported the damage induced by phenolic acids such as GA on surface properties of bacterial cells. Additionally, Perumal Samy and Gopalakrishnakone [62] attributed the antimicrobial activity of GA (3,4,5-hydroxybenzoic) against $E$. coli and

Table 4

Antimicrobial properties of active films functionalizated with GA against inoculation of Salmonella spp., Escherichia coli ATCC 25922, Staphylococcus aureus ATCC 25923, and Candida vinaria.

\begin{tabular}{|c|c|c|c|c|}
\hline \multirow[t]{2}{*}{ Microorganisms } & \multicolumn{4}{|c|}{ Observations at $24 \mathrm{~h}$} \\
\hline & Formulation & $\begin{array}{l}\text { Inhibitory zone } \\
(\mathrm{cm})\end{array}$ & Contact $^{* *}$ & Inhibition \% \\
\hline \multirow[t]{4}{*}{ Salmonella spp. } & $\mathrm{Ch}$ & $3.0(0.3)^{\mathrm{b}}$ & + & 35.9 \\
\hline & ChGA & $3.9(0.4)^{\mathrm{c}}$ & + & 57.7 \\
\hline & $\mathrm{ChN}_{\mathrm{A}}$ & $2.5(0.2)^{\mathrm{a}}$ & + & 24.8 \\
\hline & $\mathrm{ChN}_{\mathrm{B}}$ & $2.6(0.2)^{\mathrm{a}}$ & + & 25.5 \\
\hline Escherichia coli & $\mathrm{Ch}$ & $3.3(0.4)^{\mathrm{b}}$ & + & 25.6 \\
\hline \multirow[t]{3}{*}{ ATCC 25922} & ChGA & $2.8(0.3)^{\mathrm{a}}$ & + & 18.0 \\
\hline & $\mathrm{ChN}_{\mathrm{A}}$ & $3.2(0.4)^{\mathrm{b}}$ & + & 24.4 \\
\hline & $\mathrm{ChN}_{\mathrm{B}}$ & $2.7(0.2)^{\mathrm{a}}$ & + & 16.7 \\
\hline \multirow[t]{4}{*}{ Candida vinaria } & $\mathrm{Ch}$ & $3.6(0.3)^{\mathrm{b}}$ & + & 50.2 \\
\hline & ChGA & $3.9(0.3)^{\mathrm{c}}$ & + & 59.7 \\
\hline & $\mathrm{ChN}_{\mathrm{A}}$ & $2.9(0.3)^{a}$ & + & 33.9 \\
\hline & $\mathrm{ChN}_{\mathrm{B}}$ & $3.5(0.28)^{\mathrm{b}}$ & + & 48.9 \\
\hline Staphylococcus aureus & $\mathrm{Ch}$ & $2.1(0.1)^{\mathrm{b}}$ & + & 14.4 \\
\hline \multirow[t]{3}{*}{ ATCC 25923} & ChGA & $2.5(0.1)^{\mathrm{c}}$ & + & 23.8 \\
\hline & $\mathrm{ChN}_{\mathrm{A}}$ & $2.7(0.2)^{\mathrm{d}}$ & + & 27.2 \\
\hline & $\mathrm{ChN}_{\mathrm{B}}$ & $1.9(0.1)^{\mathrm{a}}$ & + & 14.1 \\
\hline
\end{tabular}

+: represents an inhibitory effect; -: represent no inhibitory effect.

*Values are measurements of diameter of inhibitory zone, expressed in $\mathrm{cm}$. The values in parentheses correspond to the standard deviation.

${ }^{* *}$ Contact area is the part of agar on Petri dish directly underneath film pieces.
S. aureus to the position and numbers of hydroxyl groups that can interact strongly with the bacteria. The site and the number of hydroxyl groups on the phenol group are thought to be related to their relative toxicity to microorganisms and are the principal structural features influencing the antioxidant capacity of phenolics, with evidence that increasing hydroxylation results in toxicity increase [61]. Romainor et al. [63] found that the antimicrobial activity against E. coli can be ascribed to the electrostatic interaction between positive charges of chitosan and negative charges from the lipopolysaccharide layer of $E$. coli that led to the break of the microbial cell wall disturbing their metabolism.

Sánchez-Maldonado et al. [64] found that the Gram-positive bacteria were generally more resistant than the E. coli strain and that the increase in the number of hydroxyl groups increased the growth inhibitory activity of the hydroxybenzoic acid [61].

According to Lattanzio [65], gallic acid inhibits the germination and sporulation of saprobe fungi. In fungi, after the cell lysis, the chitosan can attach and denaturalize the enzymes or disables the DNA and the synthesis of mRNA which does not allow the sporulation [66]. In a study by Lima [67], Candida albicans was the strain that had the greatest growth inhibition in the presence of gallic acid.

As was previously described in Section 4.1 Water-resistive properties, the swelling of ChGA was higher than that of the nanocomposites (Table 4 ). Consequently, the controlled release was principally a product of a first step of burn and the bacteriostatic effect occurred at this stage. Considering the nanocomposites, the mechanisms of control were mainly due to a swelling process which was less marked that in the case of ChGA. Consequently, the active compound was released slower maintaining the bacteriostatic effect for a relatively long period of time. Inside this latter group of nanocomposites, $\mathrm{ChN}_{\mathrm{A}}$ allowed the liberation of GA even more slowly, extending its action against the microorganisms. By virtue of this fact, $48 \mathrm{~h}$ after the beginning of the assays, $\mathrm{ChN}_{\mathrm{A}}$ conserved its antimicrobial properties to a greater degree than ChGA. These results could be attributed to encapsulation of active compound and therefore the release of GA was delayed.

\section{Conclusions}

It is worth noting that the addition of nanoparticles turned the chitosan-based matrices more hydrophobic because of a crosslinking process 
in which TPP and gallic acid were key compounds. In the latter case, GA played a triple role, not only as a crosslinking agent but also as a filmogenic suspension stabilizer and an active compound. In contact with an aqueous medium, the nanocomposites experienced a minor swelling than those matrixes with direct incorporation of GA. Consequently, films containing functionalized nanoparticles are promising as a means to develop tailor-made supports for improving the shelf stability of the active compound. The more controlled the release process the more efficient the nanocomposites as antimicrobials were.

The results suggest that these nanocomposites could be potential candidates to be used as active packages. In this sense, further studies are needed to provide an insight into potential food applications.

Supplementary data to this article can be found online at http://dx. doi.org/10.1016/j.msec.2017.05.104.

\section{Conflict of interest}

The authors declare that they have no conflicts of interest.

\section{Acknowledgments}

This work was supported by the Argentinean Agency for the Scientific and Technological Promotion (ANPCyT) (Projects PICT 2012-0415 and PICT 2014-1620) and the Argentinean National Research Council (CONICET) (PIP 2013-0109). Authors acknowledge Ing. Javier Lecot, Lic. Diana Velasco, and Sr. Daniel Russo for technical assistance.

\section{References}

[1] S. Ahmed, S. Ikram, Chitosan based scaffolds and their applications in wound healing, Achiev. Life Sci. 10 (2016) 27-37.

[2] M. Bodnar, T. Minko, J.F. Hartmann, J. Borbely, Fluorescent nanoparticles based on chitosan, NSTI-Nanotechnol. 2 (2007) 279-282.

[3] A.L. de Pinho Neves, C.C. Milioli, L. Müller, H.G. Riella, N.C. Kuhnen, H.K. Stulzer, Factorial design as a tool in chitosan nanoparticles development by ionic gelation technique, Colloids Surf., A 445 (2014) 34-39.

[4] S. Hassani, A. Laouini, H. Fessi, C. Charcosset, Preparation of chitosan-TPP nanoparticles using microengineered membranes-effect of parameters and encapsulation of tacrine, Colloids Surf., A 482 (2015) 34-43.

[5] F. Liu, J. Antoniou, Y. Li, J. Yi, W. Yokoyama, J. Ma, F. Zhong, Preparation of gelatin films incorporated with tea polyphenol nanoparticles for enhancing controlled-release antioxidant properties, J. Agric. Food Chem. 63 (15) (2015) 3987-3995.

[6] D. Alkan, L.Y. Aydemir, I. Arcan, H. Yavuzdurmaz, H.I. Atabay, C. Ceylan, A. Yemenicioglu, Development of flexible antimicrobial packaging materials against Campylobacter jejuni by incorporation of gallic acid into zein-based films, J. Agric. Food Chem. 59 (20) (2011) 11003-11010.

[7] J.S. Giftson, S. Jayanthi, N. Nalini, Chemopreventive efficacy of gallic acid, an antioxidant and anticarcinogenic polyphenol, against 1,2-dimethyl hydrazine induced rat colon carcinogenesis, Investig. New Drugs 28 (2010) 251-259.

[8] A. Chanwitheesuk, A. Teerawutgulrag, J.D. Kilburn, N. Rakariyatham, Antimicrobial gallic acid from Caesalpinia mimosoides Lamk, Food Chem. 100 (2007) 1044-1048.

[9] A.S. Hager, K.J. Vallons, E.K. Arendt, Influence of gallic acid and tannic acid on the mechanical and barrier properties of wheat gluten films, J. Agric. Food Chem. 60 (2012) 6157-6163.

[10] X. Sun, Z. Wang, H. Kadouh, K. Zhou, The antimicrobial, mechanical, physical and structural properties of chitosan-gallic acid films, LWT- Food Sci. Technol. 57 (1) (2014) 83-89.

[11] L. Stoll, T.M.H. Costa, A. Jablonski, S.H. Flôres, A. de Oliveira Rios, Microencapsulation of anthocyanins with different wall materials and its application in active biodegradable films, Food Bioprocess Technol. 9 (1) (2016) 172-181.

[12] B. Yousuf, K. Gul, A.A. Wani, P. Singh, Health benefits of anthocyanins and their encapsulation for potential use in food systems: a review, Crit. Rev. Food Sci. Nutr. (2015)http://dx.doi.org/10.1080/10408398.2013.805316.

[13] M.R. de Moura, F.A. Aouada, R.J. Avena-Bustillos, T.H. McHugh, J.M. Krochta, L.H. Mattoso, Improved barrier and mechanical properties of novel hydroxypropyl methylcellulose edible films with chitosan/tripolyphosphate nanoparticles, J. Food Eng. 92 (4) (2009) 448-453.

[14] S. Merino, C. Martín, K. Kostarelos, M. Prato, E. Vázquez, Nanocomposite hydrogels: 3D polymer-nanoparticle synergies for on-demand drug delivery, ACS Nano 9 (5) (2015) 4686-4697.

[15] P. Sugita, L. Ambarsari, Y.A. Sari, Y. Nugraha, Ketoprofen encapsulation optimization with chitosan-alginate cross-linked with sodium tripolyphosphate and its release mechanism determination using in vitro dissolution, Int. J. Res. Rev. Appl. Sci. 14 (1) (2013) 141-149.

[16] J. Lamarra, S. Rivero, A. Pinotti, Design of chitosan-based nanoparticles functionalized with gallic acid, Mater. Sci. Eng. C 67 (2016) 717-726.
[17] P. Calvo, C. Remunan-Lopez, J.L. Vila-Jato, M.J. Alonso, Novel hydrophilic chitosanpolyethylene oxide nanoparticles as protein carriers, J. Appl. Polym. Sci. 63 (1) (1997) 125-132.

[18] S. Rivero, M.A. García, A. Pinotti, Crosslinking capacity of tannic acid in plasticized chitosan films, Carbohydr. Polym. 82 (2010) 270-276.

[19] ASTM, Standard Test Methods for Water Vapor Transmission of Material, E96-95, Annual Book of ASTM, American Society for Testing and Materials, Philadelphia, PA, 1995.

[20] S. Villarruel, L. Giannuzzi, S. Rivero, A. Pinotti, Changes induced by UV radiation in the presence of sodium benzoate in films formulated with polyvinyl alcohol and carboxymethyl cellulose, Mater. Sci. Eng. C 56 (2015) 545-554.

[21] Y. Zhang, J.H. Han, Plasticization of pea starch films with monosaccharides and polyols, J. Food Sci. 71 (2006) 253-261

[22] S. Rivero, M.A. García, A. Pinotti, Composite and bi-layer films based on gelatin and chitosan, J. Food Eng. 90 (4) (2009) 531-539.

[23] V. Siracusa, I. Blanco, S. Romani, U. Tylewicz, P. Rocculi, M.D. Rosa, Poly (lactic acid) modified films for food packaging application: physical, mechanical, and barrier behavior, J. Appl. Polym. Sci. 125 (S2) (2012) 390-401.

[24] AOAC, Official Methods of Analysis of the Association of Official Analytical Chemists. 13th Edition, Washington D.C, 1980.

[25] D.R. Bhumkar, V.B. Pokharkar, Studies on effect of $\mathrm{pH}$ on cross-linking of chitosan with sodium tripolyphosphate: a technical note, AAPS PharmSciTech 7 (2006) E1-E6.

[26] M. Gierszewska-Drużyńska, J. Ostrowska-Czubenko, The Effect of Ionic Crosslinking Thermal Properties of Hydrogel Chitosan Membranes. Progress on Chemistry and Application of Chitin and Its Derivatives. Polish Chitin Society, vol. XV, MediaPress, Lodz, Poland, 2010 25-32.

[27] C. Alonso, R. Lucas, C. Barba, M. Marti, L. Rubio, F. Comellesa, J.C. Morales, L. Coderch, J.L. Parra, Skin delivery of antioxidant surfactants based on gallic acid and hydroxytyrosol, R. Pharm. Soc., J. Pharm. Pharmcol. 67 (2015) 900-908.

[28] H.-S. Kim, W.-I. Park, M. Kang, H.-J. Jin, Multiple light scattering measurement and stability analysis of aqueous carbon nanotube dispersions, J. Phys. Chem. Solids 69 (2008) 1209-1212.

[29] S. Hong, M. Kima, C.K. Hong, D. Jung, S.E. Shim, Encapsulation of multi-walled carbon nanotubes by poly(4-vinylpyridine) and its dispersion stability in various solvent media, Synth. Met. 158 (2008) 900-907.

[30] N. Cao, Y. Fu, J. He, Mechanical properties of gelatin films cross-linked, respectively, by ferulic acid and tannin acid, Food Hydrocoll. 21 (4) (2007) 575-584.

[31] V. Rubentheren, T.A. Ward, C.Y. Chee, C.K. Tang, Processing and analysis of chitosan nanocomposites reinforced with chitin whiskers and tannic acid as a crosslinker, Carbohydr. Polym. 115 (2015) 379-387.

[32] A.L. Parize, H.K. Stulzer, M.C.M. Laranjeira, I.M.D. Brighente, T.C.R.D. Souza, Evaluation of chitosan microparticles containing curcumin and crosslinked with sodium tripolyphosphate produced by spray drying, Quim Nova 35 (6) (2012) 1127-1132.

[33] F.L. Mi, S.S. Shyu, S.T. Lee, T.B. Wong, Kinetic study of chitosan-tripolyphosphate complex reaction and acid-resistive properties of the chitosan-tripolyphosphate gel beads prepared by in liquid curing method, J. Polym. Sci. B Polym. Phys. 37 (14) (1999) 1551-1564.

[34] O.V. López, L. Giannuzzi, N.E. Zaritzky, M.A. García, Potassium sorbate controlled release from corn starch films, Mater. Sci. Eng. C 33 (3) (2013) 1583-1591.

[35] K.S. Huang, A.M. Grumezescu, C.Y. Chang, C.H. Yang, C.Y. Wang, Immobilization and stabilization of $\mathrm{TiO}_{2}$ nanoparticles in alkaline-solidificated chitosan spheres without cross-linking agent, Int. J. Latest Res. Sci. Tech. 3 (2) (2014) 174-178.

[36] B. Hu, W. Yang, M. Xie, G. Hu, F. Ma, X. Zeng, Polymer nanoparticles composed with gallic acid grafted chitosan and bioactive peptides combined antioxidant, anticancer activities and improved delivery property for labile polyphenols, J. Funct. Foods 15 (2015) 593-603.

[37] U. Siripatrawan, B.R. Harte, Physical properties and antioxidant activity of an active film from chitosan incorporated with green tea extract, Food Hydrocoll. 24 (2010) 770-775.

[38] F. Niroomand, A. Khosravani, H. Younesi, Fabrication and properties of cellulosenanochitosan biocomposite film using ionic liquid, Cellulose 23 (2016) 1311-1324.

[39] Y. Sun, Y. Liu, Y. Li, M. Lv, P. Li, H. Xu, L. Wang, Preparation and characterization of novel curdlan/chitosan blending membranes for antibacterial applications, Carbohydr. Polym. 84 (3) (2011) 952-959.

[40] O. Orliac, A. Rouilly, F. Silvestre, L. Rigal, Effects of additives on the mechanical properties, hydrophobicity and water uptake of thermo-moulded films produced from sunflower protein isolate, Polymer 43 (20) (2002) 5417-5425.

[41] M. Bhattacharya, Polymer nanocomposites - a comparison between carbon nanotubes, graphene, and clay as nanofillers, Materials 9 (4) (2016) 262

[42] L.H. He, R. Xue, D.B. Yang, Y. Liu, R. Song, Effects of blending chitosan with PEG on surface morphology, crystallization and thermal properties, Chin. J. Polym. Sci. 27 (04) (2009) 501-510.

[43] K. Kanimozhi, S. Khaleel Basha, V. Sugantha Kumari, Processing and characterization of chitosan/PVA and methylcellulose porous scaffolds for tissue engineering, Mater. Sci. Eng. C 61 (2016) 484-491.

[44] S. Azizi, M.B. Ahmad, M.Z. Hussein, N.A. Ibrahim, F. Namvar, Preparation and properties of poly (vinyl alcohol)/chitosan blend bionanocomposites reinforced with cellulose nanocrystals/ZnO-Ag multifunctional nanosized filler, Int. J. Nanomedicine 9 (2014) 1909-1917.

[45] K. Kaviyarasu, D. Premanand, J. Kennedy, E. Manikandan, Synthesis of Mg doped TiO2 nanocrystals prepared by wet-chemical method: optical and microscopic studies, Int. J. Nanosci. 12 (4) (2013) 1350033-1350039.

[46] K. Kaviyarasu, E. Manikandan, J. Kennedy, M. Maaza, A comparative study on the morphological features of highly ordered $\mathrm{MgO}: \mathrm{AgO}$ nanocube arrays prepared via hydrothermal method, RSC Adv. 5 (2015) 82421-82428. 
[47] K. Kanimozhi, S. Khaleel Basha, V. Sugantha Kumari, Fabrication of chitosan based hybrid porous scaffolds by salt leaching for soft tissue engineering, Surf. Interface 1-3 (2016) 7-12.

[48] A. Sujima Anbu, S.V. Sahi, P. Venkatachalam, Synthesis of bioactive chemicals crosslinked sodium tripolyphosphate (TPP)-chitosan nanoparticles for enhanced cytotoxic activity against human ovarian cancer cell line (PA-1), J. Nanomed. Nanotechnol. 7 (2016) 1-9.

[49] A.P. Teodoro, S. Mali, N. Romero, G.M. de Carvalho, Cassava starch films containing acetylated starch nanoparticles as reinforcement: physical and mechanical characterization, Carbohydr. Polym. 126 (2015) 9-16.

[50] R.W. Korsmeyer, R. Gurny, E.M. Doelker, P. Buri, N.A. Peppas, Mechanism of solute release from porous hydrophilic polymers, Int. J. Pharm. 15 (1983) 25-35.

[51] C.K. Sahoo, S.R.M. Rao, M. Sudhakar, K. Satyanarayana, The kinetic modeling of drug dissolution for drug delivery systems: an overview, Pharm. Lett. 7 (9) (2015) 186-194.

[52] K.M. Gallagher, O.I. Corrigan, Mechanistic aspects of the release of levamisole hydrochloride from biodegradable polymers, J. Control. Release 69 (2000) 261-272.

[53] S. Rivero, M.A. García, A. Pinotti, Physical and chemical treatments on chitosan matrix to modify film properties and kinetics of biodegradation, J. Mater. Phys. Chem. 1 (3) (2013) 51-57.

[54] E. Piron, M. Accominotti, A. Domard, Interaction between chitosan and uranyl ions Role of physical and physicochemical parameters on the kinetics of sorption, Langmuir 13 (6) (1997) 1653-1658.

[55] P. Robert, P. García, N. Reyes, J. Chávez, J. Santos, Acetylated starch and inulin as encapsulating agents of gallic acid and their release behaviour in a hydrophilic system, Food Chem. 134 (2012) 1-8.

[56] S. Rivero, Thesis: Estudio y aplicación de películas activas a base de quitosano, Faculty of Engineering, UNLP, La Plata, Argentina, 2012.

[57] C. Lopez de Dicastillo, C. Nerin, P. Alfaro, R. Catala, R. Gavara, P. Hernandez-Muñoz Development of new antioxidant active packaging films based on ethylene vinyl alcohol copolymer (EVOH) and green tea extract, J. Agric. Food Chem. 59 (2011) 7832-7840.
[58] O.L. Ramos, A.C. Santos, M.V. Leão, J.O. Pereira, S.I. Silva, J.C. Fernandes, M.I. Franco, M.E. Pintado, F.X. Malcata, Antimicrobial activity of edible coatings prepared from whey protein isolate and formulated with various antimicrobial agents, Int. Dairy J. 25 (2012) 132-141.

[59] M. Magdalane, K. Kaviyarasu, J. Vijaya, B. Siddhardha, B. Jeyaraj, Photocatalytic activity of binary metal oxide nanocomposites of $\mathrm{CeO}_{2} / \mathrm{CdO}$ nanospheres: investigation of optical and antimicrobial activity, J. Photochem. Photobiol. B Biol. 163 (2016) 77-86.

[60] M. Magdalane, K. Kaviyarasu, J. Vijaya, C. Jayakumar, M. Maaza, B. Jeyaraj, Photocatalytic degradation effect of malachite green and catalytic hydrogenation by UV-illuminated $\mathrm{CeO}_{2} / \mathrm{CdO}$ multilayered nanoplatelet arrays: investigation of antifungal and antimicrobial activities, J. Photochem. Photobiol. B Biol. 169 (2017) 110-123.

[61] A. Borges, C. Ferreira, M.J. Saavedra, M. Simões, Antibacterial activity and mode of action of ferulic and gallic acids against pathogenic bacteria, Microb. Drug Resist. 19 (4) (2013) 256-265.

[62] R. Perumal Samy, P. Gopalakrishnakone, Therapeutic potential of plants as anti-microbials for drug discovery, Evid. Based Complement. Alternat. Med. 7 (2010) 283-294.

[63] A.N.B. Romainor, S.F. Chin, S.C. Pang, L.M. Bilung, Preparation and characterization of chitosan nanoparticles-doped cellulose films with antimicrobial property, J. Nanomater. 130 (2014) 1-10.

[64] A.F. Sánchez-Maldonado, A. Schieber, M.G. Ganzle, Structure-function relationships of the antibacterial activity of phenolic acids and their metabolism by lactic acid bacteria, J. Appl. Microbiol. 111 (2011) 1176-1184

[65] V. Lattanzio, V.M. Lattanzio, A. Cardinali, Role of phenolics in the resistance mechanisms of plants against fungal pathogens and insects, Phytochemistry: Advances in Research, Chapter 2Filippo Imperato Research Signpost 2006, pp. 23-67.

[66] G.A. Valencia, Efecto antimicrobiano del quitosano: Una revisión de la literatura, Rev. Sci. Agroalimentaria 2 (2015) 32-38.

[67] V.N. Lima, C.D. Oliveira-Tintino, E.S. Santos, L.P. Morais, S.R. Tintino, T.S. Freitas, ... H.D. Coutinho, Antimicrobial and enhancement of the antibiotic activity by phenolic compounds: gallic acid, caffeic acid and pyrogallol, Microb. Pathog. 99 (2016) 56-61. 